\title{
¿Qué es esa cosa llamada Arqueología Histórica?
}

\author{
What is this Thing Called Historical Archaeology?
}

\author{
Sandra Montón Subías \\ ICREA/Dpto. de Humanidades. Universitat Pompeu Fabra (UPF) \\ sandra.monton@upf.edu \\ Luis J. AbeJEZ \\ LAB-PATC, Red IBERTUR-Universitat de Barcelona (UB) \\ abejez@gmail.com
}

Recibido: 27-01-2015

Aceptado: 23-03-2015

\begin{abstract}
RESUMEN
La arqueología histórica, en su sentido cronológicamente restringido, en tanto que estudio de los procesos que dieron lugar a la formación del mundo moderno y a su evolución posterior, va cobrando paulatina fuerza en la academia de nuestro país. Este artículo quiere contribuir a generar más debate al respecto, revisando cómo se sitúa la arqueología histórica española en el panorama internacional y algunas de sus particularidades más significativas. Al hacerlo, incide también en los estrechos vínculos que unen a la arqueología histórica y a la prehistórica desde sus origenes, tanto en lo que se refiere a la demarcación ontológica, epistemológica y metodológica de la primera como a la influencia de las inquietudes socio-políticas de la arqueología histórica en la prehistoria. Esta reflexión está en parte situada desde la prehistoria ya que, como está ocurriendo en otros casos, una de las firmantes de este artículo procede de esta disciplina.
\end{abstract}

Palabras clave: arqueología histórica, prehistoria, convergencia metodológica, mundo moderno.

\begin{abstract}
Historical archaeology, in its narrow temporal sense -as an archaeology of the emergence and subsequent evolution of the Modern world-is steadily taking pace in Spanish academia. This paper aims at provoking a more robust debate through understanding how Spanish historical archaeology is placed in the international scene and some of its more relevant particularities. In so doing, the paper also stresses the strong links that have united historical and prehistorical archaeology since its inception, both in relation to the ontological, epistemological and methodological definition of the first as to the influence of socio-political issues in the latter. Such reflection is partly a situated reflection from prehistory as one of the paper's authors has been a prehistorian for most of her professional life.
\end{abstract}

Key words: Historical Archaeology, Prehistory, Methodological Convergence, Modern World. 


\section{Introducción}

En 1976, Alan F. Chalmers publicó un libro ahora archiconocido -¿Qué es esa cosa llamada ciencia?- para servir de introducción a los puntos de vista modernos sobre la naturaleza de la ciencia. Este artículo, salvando las distancias, replica parte del título de ese libro y, como él, también quiere esbozar un estado de la cuestión, aunque en este caso sea para debatir sobre arqueología histórica -esa subdisciplina todavía poco conocida en nuestro país- y tenga pretensiones menos universalistas, pues se dirige, principalmente, a un público español.

La respuesta a qué es la arqueología histórica ejemplifica bien lo difícil que resulta consensuar definiciones en las Ciencias Sociales y las $\mathrm{Hu}-$ manidades. Dependiendo, entre otros aspectos y como veremos después, de las distintas tradiciones académicas y de los contextos políticos en los que se ha utilizado y sigue utilizándose esta rúbrica, se entiende y concibe de manera diferente, lo que ha provocado un interesante debate sobre su estatuto ontológico, epistemológico y metodológico y, por lo tanto, sobre su afiliación, definición y ámbito de aplicación. De hecho, se ha llegado a tildar de confusa -e incluso de molesta- la situación que se genera de esta falta de acuerdo (Orser 1996; Funari et al. 1999; Connah 2007). Además, en algunos países, como en España, el adjetivo "histórica" para calificar solo a cierto tipo de arqueología se recibe normalmente con una cierta sorpresa.

Frente a quienes opinan que la arqueología histórica se refiere a la investigación de todos aquellos períodos que cuentan con fuentes escritas (Wesler 1996; Andrén 1998; Funari et al. 1999; Funari 2008), la tendencia mayoritaria la circunscribe al estudio de los procesos que dieron lugar a la formación del mundo moderno y a su evolución posterior hasta nuestros días (Walker 1967; Deetz 1977; Orser 1996, 2012; Mayne 2008; Pykles 2010; Schuyler 2010). Se puede afirmar, por tanto, que desde un punto de vista puramente cronológico existe una definición amplia de la arqueología histórica y otra más restringida, y que ambas implican posicionamientos diferentes por parte de los y las profesionales que las defienden, lo que genera, inevitablemente, cuestionamientos mutuos y controversias de distinta índole. No obstante, aunque las divergencias continúan estando presentes, la situación comienza paulatinamente a estandarizarse debido, en gran medida, a la innegable influencia que la arqueología histórica estadounidense -que defiende, mayoritariamente, una perspectiva cronológicamente restringida- ejerce en el panorama internacional.

Por los motivos que expondremos después, nosotros también preferimos el uso cronológicamente restringido del término. Por ello, de ahora en adelante, cuando nos refiramos a él, lo haremos en este sentido. En este artículo veremos cómo se sitúa la arqueología española en este debate internacional y nos detendremos en algunas de las características que a nosotros nos parecen más significativas: su escasa presencia en la academia española, y el reciente interés por el estudio del colonialismo hispano-portugués de época moderna, un área temática que ilustra bien la particular relación que puede establecerse entre la arqueología histórica y la prehistórica. Para ello, primero revisaremos, aunque de modo breve, las dos perspectivas principales a las que nos hemos referido y las principales concurrencias entre la arqueológica histórica y la prehistórica.

A primera vista, podría sorprender que un artículo como éste, de arqueología histórica, se presente en una revista tradicionalmente más orientada a temas prehistóricos. Sin embargo, los vínculos entre la arqueología histórica y la prehistoria son robustos y firmes desde sus orígenes. Más adelante nos ocuparemos con mayor extensión de esta cuestión, pero baste decir ahora que en EE.UU., cuna de esta subdisciplina, sus raíces intelectuales se hunden en el campo de la prehistoria

(...) because that field saw its main development in departments of anthropology, where prehistoric archaeology has a long tradition $^{1}$ (Deetz 1991: 2).

Sea en su versión restringida o amplia, su demarcación se vincula al trazado de la línea que separa a las sociedades prehistóricas de las históricas. Es muy interesante que, en España, algunos de sus practicantes procedan del campo de la prehistoria, algo que también sucedió en los contextos pioneros. En el primer número de Historical Archaeology, publicado en 1967, Ian Walker explicó su experiencia personal en este sentido, una experiencia que se añadía a la que vivieron otros antes que él (Schuyler 2003; Veit 2007). Y es que, a pesar de los esfuerzos por singularizarse como subdisciplina, en EE.UU. la arqueología histórica y la prehistórica han convivido en estrecha conexión desde sus orígenes. Sus márgenes se entrelazan, como bien explicitó 
Bernard L. Fontana ya en 1965, hasta el punto de que cualquier discusión conceptual sobre la una lleva, inevitablemente, a discutir sobre la otra. Por ello, la comprensión de la trayectoria historiográfica de ambas se enriquece al considerarlas conjuntamente. De hecho, diferentes trabajos han profundizado en su interrelación, sobre todo por lo que se refiere a la necesidad de situar eventos coyunturales en cadenas históricas más dilatadas, aplicar perspectivas comparativas entre nuestros pasados más remotos y más recientes y comprender la influencia que la arqueología histórica ha tenido en la teoría y práctica de la arqueología como disciplina (p. ej. Lightfoot 1995; Wilkie 2005; Taylor 2008).

Aunque en nuestro país la trayectoria de la arqueología histórica no tiene el suficiente recorrido como para poder valorar su contribución a la prehistoria, y viceversa (ver Wilkie 2005 para EE.UU.), sí comienza a apreciarse una implicación creciente de prehistoriadores y prehistoriadoras en proyectos relacionados con la arqueología histórica. Algunos de estos proyectos, como los que se centran en el estudio del colonialismo hispano-portugués moderno, se interesan por procesos históricos de muy larga duración que afectaron a sociedades orales con grados de complejidad socio-económica muy variados, entre las que se encuentran grupos de caza y recolección o agricultores similares a los que protagonizaron la prehistoria. Por lo tanto, generan problemáticas que incumben -o deberían incumbir- a la prehistoria y a sus investigadores. El análisis del contacto colonial con estos grupos puede ofrecer información de interés para prehistoriadores y prehistoriadoras al iluminar aspectos de su comportamiento no visibles cuando se estudian en tanto que procesos aislados.

Además, a título más personal, queremos recoger la invitación que Laurie Wilkie (2005) lanzó hace ahora 10 años en World Archaeology sobre la conveniencia de publicar más trabajos de arqueología histórica en revistas de prehistoria (o de tradición mayoritariamente prehistórica en el caso que nos ocupa). Como ella, pensamos que se trata de una de esas ventajosas alianzas en las que ambas partes salen beneficiadas.

\section{Las diferentes concepciones de la Arqueología Histórica}

Aunque, como ya apuntaran Martin Hall y Stephen W. Silliman, la arqueología histórica means different things to different people ${ }^{2}$ (2006: 1), lo cierto es que, grosso modo, y como acabamos de mencionar, coexisten en la actualidad dos grandes concepciones de la misma: la que engloba el estudio de cualquier cultura que cuente con un registro escrito y la que lo acota al de los procesos de interacción que, entre diferentes pueblos, se iniciaron con la expansión (y posterior invasión, conquista y colonización) europea por el mundo a finales de la Baja Edad Media. No obstante, ambas concepciones comparten, al menos en sus inicios, el interés por diferenciarse de la arqueología prehistórica.

El término "arqueología histórica" empezó a generalizarse en y desde Estados Unidos a partir del curso que, con este mismo nombre, impartió John L. Cotter en la Universidad de Pennsylvania durante el año académico de 1966-67. En aquellos momentos también tuvo lugar la celebración de la International Conference on Historical Archaeology en Dallas (1967); la formación de la Society of Historical Archaeology (SHA) (1967); y la aparición del primer número de su revista, Historical Archaeology (1969). Anteriormente, en lo que Benjamin C. Pykles (2008) ha denominado como período formativo, ya se había utilizado el mismo término (Treganza 1954; Harrington 1955) u otros semejantes -Historic Site Archaeology, Historic Archaeology, o Historic Sites Archaeology- para describir los trabajos realizados en yacimientos históricos -posteriores a 1492- de los Estados Unidos. No obstante, estos trabajos estaban fundamentalmente orientados a la conservación, restauración y puesta en valor de estos lugares, pero no ahondaban en el estudio de los procesos históricos que representaban (para profundizar en el desarrollo histórico de la disciplina ver, por ejemplo, Schuyler 1970; Cotter 1993; South 1994; Veit 2007).

De este modo, sus intereses se circunscribieron inicialmente al periodo de contacto entre europeos y nativos americanos y a la excavación de lugares euroamericanos emblemáticos, como Williamsburg o Jamestown entre otros. No hay que olvidar que, originalmente, esta arqueología de los sitios históricos fue una empresa política de afirmación nacional (Schuyler 1976; Deagan 1996, Little 2007), por lo que resultaba muy necesario buscar nuevas evidencias materiales que pudieran corroborar o dimensionar acontecimientos ya conocidos por las fuentes escritas y, de esta manera, construir un patrimonio arqueológico sobre los orígenes de la nación americana. En este sentido, este tipo de arqueología histórica 
jugó en EE.UU. un papel similar al que tuvo la arqueología prehistórica en algunos estados europeos o la arqueología prehispánica en otras partes de América (ver, por ejemplo, Abejez 2011).

Al ser entendida de esta forma, implícitamente se estableció una distinción entre el estudio arqueológico de la presencia europea en el continente americano y el de los pueblos nativos anteriores a ella, es decir, entre la arqueología histórica y la arqueología prehistórica, aunque la mayoría de sus practicantes hubiesen sido primero prehistoriadores o conjugaran una y otra en su trabajo de campo (Schuyler 2003). Esta voluntad separatista se ha ido dulcificando con el paso del tiempo, hasta el punto de alentarse incluso su disipación (ver Lightfoot 1995; Wilkie 2005).

A diferencia de la europea, la arqueología prehistórica norteamericana estableció vínculos estrechos con la antropología cultural desde sus inicios. La concepción del propio objeto de estudio tuvo mucho que ver en ello. Las y los antropólogos/ arqueólogos norteamericanos podían pasar de una disciplina a otra con facilidad, dado que los descendientes de algunos de los pueblos del pasado que estudiaban a partir de sus restos materiales seguían viviendo en el presente (Caldwell 1959). La pervivencia de estos grupos indígenas y el potencial interpretativo que suponía que algunos de ellos hubiesen podido mantener ciertas tradiciones y formas de vida ancestrales que también podían hallarse en el registro arqueológico explica por qué las inferencias etnoarqueológicas se difundieron y aplicaron -no sin serias críticas y objeciones (Politis 2002)- por todo el continente americano.

En este contexto no resulta sorprendente que la propuesta de crear una sociedad de arqueología histórica empezara a gestarse en el seno de la triple A -Asociación de Antropología Americana (AAA)- durante la celebración de su congreso anual en 1958, aunque no se institucionalizó hasta 1968 (Schuyler 2003). En los años inmediatamente posteriores, el debate sobre la filiación -histórica o antropológica- de la arqueología histórica alcanzó su punto más enardecido, aunque sin llegar a un consenso sobre la cuestión (Cleland y Fitting 1968; Orser 1996, 2000; Wilkie 2005). Desde ambas posturas, no obstante, se entendió que la arqueología histórica debía de ocuparse de los procesos posteriores a la llegada de Colón al continente americano.

A partir de entonces, empezaron a ampliarse sus intereses -que hasta aquel momento se habían circunscrito al periodo de contacto entre nativos y europeos- con la incorporación de problemáti- cas de cronología posterior y cuestiones referentes a las poblaciones afro- y asio-americanas (Deetz 1977; Schuyler 2003), recogiendo también en este caso las preocupaciones políticas que se habían generado en el seno de diferentes movimientos políticos por la lucha de los derechos civiles en EE.UU., Australasia y África (Little 2007; Mayne 2008). Resulta indudable que la arqueología, en general, y la arqueología histórica, muy en particular, no han sido nunca ajenas a los acontecimientos e intereses políticos del contexto en el que se han ido fraguando. De este modo, las construcciones sobre el pasado varían en función de las distintas ideologías e intereses que se abrigan desde el presente en el que se escriben (ver al respecto Lowenthal 1985; Tarble 2015).

Dado que en EE.UU. la escritura -el criterio principal que se utiliza para trazar la divisoria entre prehistoria e historia- se introdujo con la llegada de los europeos, la arqueología de los pueblos con escritura y la arqueología de los procesos de expansión europea encajaban a la perfección, tanto cronológica como conceptualmente. Por este motivo, en el trabajo pionero In Small Things Forgotten, James Deetz afirmaba, con muy pocas líneas de diferencia, que la arqueología histórica

(....) studies the cultural remains of literate societies that were capable of recording their own history ${ }^{3}$,

y que

is the archaeology of the spread of European cultures throughout the world since the fifteenth century, and their impact on and interaction with the cultures of indigenous peoples $^{4}$ (1977: 5),

sin que ello le supusiera ninguna contradicción.

En la actualidad, y en líneas generales, esta conceptualización cronológica de la arqueología histórica continúa siendo la más aceptada y practicada, dentro y fuera de los Estados Unidos (Hall 2000; Therrien 2002; Hall y Silliman 2006; Senatore 2007; Charlton y Fournier 2008; Orser 2012; Mehler 2013; Blouet 2014; Smith 2014; Azkárate y Escribano 2015; Cruz Berrocal 2015, son tal solo algunos ejemplos). Simplemente con revisar las comunicaciones que se presentan anualmente en los congresos de la Society of Historical Archaeology (SHA) o los artículos que se publican en las revistas de arqueología histórica nos daremos cuenta de que, en su práctica totalidad, se refieren a acontecimientos acaecidos en los últimos 500 años. La propia página web de la SHA (http:// 
www.sha.org) incide en esta idea, al acotarla a la investigación sobre el Mundo Moderno.

Obviamente, existen algunas divergencias que, sobre todo, se han ido manifestando a medida que esta acepción se ha popularizado y difundido. Por ejemplo, se puede discrepar sobre el momento a partir del cual es posible hablar con propiedad de Arqueología Histórica -1415, 1450, 1492, 1510, 1553, etc.- dado que la expansión moderna de los países europeos fue progresiva y comenzó con anterioridad a su llegada al continente americano, con las expediciones portuguesas y castellanas por el norte de África y el Atlántico desde principios del siglo XV. No obstante, como escribió Orser (1996), no importa tanto fijar fechas concretas -que aunque gocen de consenso no dejan por ello de ser arbitrarias (Schuyler 1970; Orser y Fagan 1995)- como defender que la arqueología histórica se centra en el estudio de la formación y evolución posterior del mundo moderno. La investigación sobre la génesis y desarrollo de procesos como el colonialismo, el capitalismo, el eurocentrismo o el racismo y la racialización enmarcarían esta subdisciplina (Walker 1967; Schuyler 1970; Deetz 1977; Leone y Potter 1988, 1999; Johnson 1996; Orser 1996, 2012; Mayne 2008; Pykles 2010).

Junto a la anterior interpretación, otros y otras arqueólogos, sobre todo -aunque no sólo- de fuera de los EE.UU., entienden que la arqueología histórica debería de ir más allá de épocas recientes -por importantes que se consideren para entender nuestro presente- e incluir la arqueología de cualquier período que cuente con documentación escrita (Posnasky y DeCorse 1986; Little 1992, 1994; Wesler 1996; Andrén 1998; Funari et al. 1999; Moreland 2001; Funari 2008), aunque muchos de ellos restrinjan su práctica arqueológica al estudio de cronologías posteriores al 1500 . Se plantea así una lectura cronológicamente amplia de la arqueología histórica, en el sentido de interpretarla genéricamente como el estudio de las sociedades con escritura y no de un determinado periodo histórico o de un sistema económico. De esta forma, su ámbito de aplicación cronológico y geográfico varía ineludiblemente: en determinadas zonas -especialmente del Viejo Mundopuede abarcar varios miles de años, mientras que en otras áreas geográficas apenas comprende unos cientos.

Muchos de quienes defienden un uso cronológicamente tan holgado de la arqueología histórica encuentran su razón de ser en la metodología común que implica tratar con fuentes de infor- mación -documentos históricos- distintas a la cultura material, que es precisamente lo que define metodológicamente a la arqueología prehistórica (Little 1992, 1994; Wesler 1996; Andrén 1998; Moreland 2001). Esta perspectiva ha sido criticada con rotundidad por tratarse de una generalización falaz que ignora las peculiaridades ineludibles que los textos escritos tienen en cada momento y contexto histórico (Mehler 2012), a las que deben añadirse las propias de la historia oral. En un breve y muy sugerente artículo que raramente se cita, quizás porque se publicó en una revista de ámbito regional, Kit W. Wesler (1996) interrogaba sobre los efectos estructurales de la escritura en las sociedades humanas y cómo esto podría definir conceptualmente la disciplina. Desafortunadamente, después de él, solo muy pocos se han planteado reflexionar sobre el sentido que podría tener reunir todos los periodos con escritura preguntándose por las procesos históricos y características estructurales que son comunes en las sociedades que la han incorporado (Funari et al. 1999). Además, lo han hecho de modo somero y sin generar un debate significativo.

Tradicionalmente, no obstante, en el Viejo Mundo se han utilizado denominaciones más específicas -relacionadas con la cronología y/o la cultura- para cada una de las diferentes arqueologías referidas a sociedades con escritura (Arqueología de Grecia, de China, de Roma, Bíblica, Medieval, Industrial o Post-medieval, por citar algunos ejemplos) (Funari 1999; Hall y Silliman 2006). No ha existido una preocupación real por reflexionar sobre lo que todas ellas podían compartir teórica y metodológicamente al no concebirse como subconjuntos de un todo más amplio que no fuese la arqueología en general. Es importante tener en cuenta, por tanto, que en las tradiciones académicas europeas la etiqueta "arqueología histórica" es ajena a su propio desarrollo intelectual y que los motivos por los que se ha incorporado son muy distintos a los del contexto en el que se generalizó. En este sentido cronológico amplio, puede ser simplemente un préstamo al que adherirse acríticamente por la influencia de la arqueología norteamericana, pero puede ser también una reacción ante la sensación de "hurto" que ha provocado secuestrar el calificativo de histórico para cronologías tan recientes. Ciertamente, para gran parte de quienes se encuentran en la órbita de la arqueología europea sorprendió que la calificación "histórica" pudiese ser excluyente pues, en el Viejo Mundo, "toda" la arqueología -incluida la prehistórica- se asocia directa- 
mente con la Historia desde sus mismos orígenes, y se concibe como histórica, en el sentido de que produce (o al menos lo intenta) conocimiento histórico. Por ello Hicks y Beaudry comentaron que la noción de arqueología histórica, en estos países, podría resultar "tautológica" (2006: 1).

De todos modos, esta acepción temporalmente amplia de la arqueología histórica no se ha convertido en una tendencia mayoritaria. En Europa -y en otras partes del mundo también- la investigación se encuentra a gusto con las etiquetas tradicionales relacionadas con la división convencional del "tiempo histórico" y, más allá de la incomodidad que le pueda provocar el calificativo de histórica para referirse únicamente a un determinado periodo, no ha respondido generalmente a la llamada unificadora. Curiosamente, además, una de estas etiquetas -la de Arqueología Postmedieval- comprende una cronología coincidente grosso modo con la de la arqueología histórica norteamericana. También aquí, concretamente en el Reino Unido, se fundó la Society for Post-Medieval Archaeology (SPMA, http:// www.spma.org.uk/) en 1966 para promover la investigación arqueológica del periodo que, en Europa, comprendía desde los últimos momentos de la Edad Media hasta la Industrialización, $\mathrm{y}$, fuera de ella, los procesos relacionados con el colonialismo europeo. Posteriormente, otros países europeos han seguido la iniciativa británica (Mehler 2012). En la actualidad, y tras una serie de discusiones sobre sus límites cronológicos, la propia SPMA, junto a otros investigadores e investigadoras, defiende que se extienda hasta nuestros días (Gilchrist 2005; Barrachina y Escribano 2012; Mehler 2012; Dalglish 2013).

\section{La convergencia entre Arqueología Histórica, Arqueología Prehistórica e Historia}

Gran parte de la reflexión sobre la convergencia entre la arqueología histórica y la prehistórica se ha aglutinado en torno a la comprensión de los procesos de colonialismo y contacto cultural entre poblaciones. En sintonía con las líneas planteadas primero por la Escuela de los Anales y más tarde por la Historia del Mundo, se ha resaltado, especialmente, la perspectiva temporal de largo alcance característica de la prehistoria, aunque sin olvidar la importancia de los contextos locales y las perspectivas microhistóricas enfatizadas por los trabajos tradicionales de arqueología histórica. Analizar los procesos coloniales contemplando su inserción en cadenas temporales extensas que incluyan las secuencias previas al contacto de las poblaciones locales permite entender mejor las dinámicas sociales de cambio, permanencia y transformación, los mecanismos mediante los que éstas se articulan y su verdadera magnitud. Como apuntara Lightfoot (1995: 200), esta perspectiva prehistórica, resulta indispensable para

(....) undertake comparative analyses of cultural transformations that took place before, during, and after European contact and colonialism $^{5}$.

Una mirada en el sentido contrario resulta también muy provechosa, pues muchas de las inquietudes socio-políticas sentidas y vividas primeramente en la arqueología histórica han repercutido muy significativamente en el desarrollo de la prehistoria, tanto por lo que se refiere a sus interpretaciones como al código deontológico que rige el ejercicio de la profesión (Wilkie 2005). No hay que olvidar que el hecho de que la arqueología histórica trate sobre procesos históricos (recientes) cuyas heridas no han sanado todavía para sectores importantes de la población le confiere una carga emocional extra y un mayor compromiso político; algo parecido, no obstante, a lo que también ocurre al trabajar con sociedades prehistóricas de América, África y Oceanía, donde grupos importantes de las poblaciones actuales sienten con ellas vínculos mucho más estrechos de los que experimenta la mayor parte de la población en el entorno del "Viejo Mundo" (ver, por ejemplo, Campbell 2008). Especial mención merece el afán por implicar e incorporar a las comunidades locales en la práctica arqueológica y por integrar tanto la multivocalidad en la explicación del pasado como todas aquellas preocupaciones que se hallan tras el desarrollo de la public archaeology.

Además, los trabajos de arqueología histórica pueden convertirse en una poderosa herramienta de inspiración para la interpretación y análisis de contextos prehistóricos. Continuando con el ejemplo anterior sobre los procesos de contacto cultural y colonialismo, la arqueología histórica puede aportar -y lo ha hecho- marcos de referencia para entender algunos de los que acaecieron en tiempos más pretéritos (el caso más extremo sería el de Gilbert B. Tostevin (2007), que alude a su ductilidad para entender la interacción entre Neandertales y Sapiens y entre el 
Auriñaciense y el Chatelperroniense). La cultura material no necesariamente se utilizó en el pasado respondiendo a nuestra lógica. Por lo tanto, atender a su comportamiento cuando contamos con otras fuentes de información puede aportar nuevas lecturas, del mismo modo que el material arqueológico complementa e incluso contradice interpretaciones basadas únicamente en las fuentes escritas. Por ejemplo, diferentes estudios sobre la producción y uso de cerámicas en la América colonial han desencializado su pretendida "etnicidad" o su asociación con una determinada categoría social, sugiriendo situaciones más complejas que las imaginadas previamente (p. ej. Ferguson 1980; Deagan 1983; Orser 1996; Jamieson 2004; Rodríguez-Alegría 2005; Voss 2012). En este sentido, la arqueología histórica puede aportar elasticidad y flexibilidad a la prehistoria.

De hecho, arqueólogos que trabajan en EE.UU., Australia y África han defendido una visión de la arqueología que evite posibles cismas entre la arqueología histórica y la prehistórica, e incluso han propuesto disolver sus límites temporales (Lightfoot 1995; Wesler 1996; Connah 1998, 2007; Fredericksen 2000; Wilkie 2005; Schmidt 2006) por tratarse de una separación calificada de artificial (Wilkie 2005). A pesar de ello, el debate sobre su separación no se ha zanjado. Roberta Gilchrist lo resumió bien en la presentación que hizo para World archaeology al comentar que

(....) Historical archaeology's relationship to prehistory remains problematic (...), sometimes offering itself as a proving ground for archaeological theory and method, at other times striving stubbornly for an independent agenda ${ }^{6}$ (Gilchrist 2005: 331).

Aunque es difícil predecir lo que sucederá en España si la arqueología histórica continúa ganando importancia, puede que éste no sea aquí un debate tan significativo. Por ejemplo, los proyectos académicos sobre colonialismo hispanoportugués que mencionaremos en la siguiente sección evitan esta bipolaridad y resultan un buen modelo de integración arqueológica. Aunque aglutinados en torno al estudio de procesos coloniales de la era moderna, investigan secuencias culturales mucho más amplias que incluyen el desarrollo (pre)histórico de las poblaciones locales. En nuestra opinión, no se trata tanto de maximizar o minimizar las diferencias entre la prehistoria y la arqueología histórica, sino de reconocerlas y ser conscientes de ellas para obtener el máximo partido de ambas.

Estrechar los lazos con la prehistoria y diseñar proyectos de investigación transversales no significa olvidar ni las singularidades de la arqueología histórica ni que algunas de sus demandas concretas son diferentes a las de la prehistoria. Minusvalorar las diferencias entre ambas, reduciéndolas a aspectos puramente cuantitativos (cantidad y variedad de materiales recuperados y proximidad en el tiempo) como pretenden, por ejemplo, Dan Hicks y Mary C. Beaudry (2006) nos parece desacertado. La arqueología histórica suma a la información arqueológica la procedente de las fuentes escritas (primarias y secundarias) y, muy a menudo, sobre todo para sus épocas más recientes, la historia oral. Así, incorpora a las herramientas habituales de la prehistoria una panoplia de disciplinas que permiten realizar una lectura de amplio espectro de la realidad del pasado, lo que, dicho sea de paso, también necesariamente implica una formación profesional más interdisciplinar. De todos modos, un buen número de trabajos en Sudamérica, África y Oceanía están integrando las fuentes escritas y la historia oral al estudio de la prehistoria, la "memoria prehistórica" (Wiley 2008), siendo particularmente significativos para el área de Oceanía (Campbell 2002, 2008; Sheppard et al. 2004).

Esta especificidad de la arqueología histórica ya fue destacada en los trabajos clásicos de la disciplina (Noël Hume 1964; Deetz 1977). Se podría objetar, sin embargo, que la arqueología debe concentrarse únicamente en el estudio y recuperación de la cultura material, y que, por ello, un buen arqueólogo puede excavar en cualquier yacimiento, independientemente de su cronología. Jean Carl Harrington (1955) o Ian Walker (1967), otros pioneros de la arqueología histórica, ya alertaron sobre esta objeción y sobre lo perjudicial que podría ser considerar al arqueólogo únicamente como un técnico capaz de excavar en cualquier lugar. Aunque es verdad que con un buen conocimiento de las técnicas y de los métodos de excavación, y un pequeño reciclaje en las cronologías pertinentes, ello es perfectamente plausible, la cuestión de fondo es otra. Se refiere a la contribución de la arqueología en la generación y solución de problemáticas históricas y, por consiguiente, en la producción del conocimiento histórico. Concierne, por lo tanto, a la propia dimensión ontológica de la arqueología histórica: ¿debe ser una disciplina auxiliar de la historia o una disciplina que trabaje en igualdad de condiciones junto a otras? 
Si nos decantamos por la segunda opción, es decir, si buscamos que la arqueología contribuya al conocimiento del pasado reciente en tanto que disciplina, debemos proponer preguntas generadas desde nuestra propia "disciplinidad" y no limitarnos a resolver preguntas planteadas desde otras. Para ello, precisamos considerar el extenso conjunto de fuentes de información al que nos referíamos anteriormente y conocer sus pormenores. Aunque resulta imposible ser experto en todas ellas (para ello se reivindica trabajar interdisciplinariamente), sí es necesario saber manejarlas críticamente $\mathrm{y}$, sobre todo, conocer el contexto en el que se generaron y los sesgos que pueden devenir de ello (ver, p. ej. Deagan y Scardaville 1985; Lightfoot 1995; Courtney 2007; Mehler 2012). Si no es así, la elaborada crítica que la arqueología ha hecho a las fuentes escritas puede acabar convirtiéndose en una consigna que se repite en artículos y presentaciones académicas pero que tiene pocas implicaciones reales en la práctica arqueológica. Tuvimos ocasión de comprobar este riesgo recientemente, en una sesión que uno de nosotros co-organizó sobre la arqueología del colonialismo español en el Pacífico en la reunión anual que la Sociedad de Arqueología Americana (SAA) celebró en Honolulu en 2013. En esa ocasión, fue precisamente un historiador quien alertó sobre los peligros de un uso acrítico de las fuentes escritas a una arqueóloga que las había interpretado demasiado literalmente.

Así pues, la arqueología histórica necesita aunar un conocimiento y uso crítico de las fuentes escritas y de la cultura material del pasado, dado que ambos tipos de información resultan complementarios. Precisamente, ese manejo de diferentes tipos de evidencia la emplaza en una situación de privilegio para, desde una perspectiva comparada, reflexionar y profundizar sobre las singularidades y potencialidades de la cultura material como fuente de información histórica, reflexión de la que se puede beneficiar la prehistoria. Desde un punto de vista metodológico, posiblemente este eclecticismo sea su rasgo más distintivo. $\mathrm{Su}$ uso combinado

(...) should permit us to say something about the past that could not have been said using only one set of data. This criterion is the most critical to be applied to avoid the charge often heard that historical archaeology is "an expensive way of learning what we already know"'7 (Deetz 1996: 32).
La cita anterior de James Deetz nos sitúa de pleno en la dinámica que ha caracterizado la relación entre la arqueología histórica y la historia en el marco del particular triángulo prehistoriaarqueología histórica-historia; una relación en la que la arqueología histórica se ha sentido a menudo ignorada, "utilizada" e infravalorada. De ahí el célebre apodo handmaiden to history ${ }^{8}$ que Ivor Noël Hume acuñó en 1964 para referirse a su condición subordinada como auxiliar de la historia. Sin duda, esta fue la finalidad de muchas de las primeras excavaciones que se llevaron a cabo en los denominados yacimientos históricos (historic sites archaeology) en los EE.UU. (Moreland 2006; Little 2007).

Más recientemente, sin embargo, algunos historiadores han expresado un malestar parecido. Paul Courtney, arqueólogo e historiador a la vez, comentaba que

(....) historians working on archaeological projects as ancillary consultants often feel their work is poorly edited and, indeed, "castrated" by "myopic" archaeological team leaders ${ }^{9}$ (2007: 41).

No obstante, al menos hasta la fecha, ha sido mucho más común que se profundizara sobre esta relación desde la arqueología (p. ej. Noël Hume 1964; Deagan y Scardaville 1985; Jack 1993; Courtney 2007; Little 2007) que desde la historia (aunque ver Carment 1993 y Mayne 2008), y casi siempre en plataformas (congresos, reuniones, publicaciones, etc.) vinculadas al colectivo arqueológico. Probablemente, la arqueología histórica se encuentre todavía insegura en su convivencia con la historia, y menos afianzada en el nicho específico que deba ocupar en la contribución al conocimiento histórico. Y lo mismo podríamos señalar de su relación con la prehistoria (Little 1994). Probablemente, por su carácter híbrido, la arqueología histórica tiene que reflexionar más sobre su propia naturaleza, y ello necesariamente pasa por inquirir en los vínculos que la unen y separan de las otras dos. En cualquier caso, y parafraseando a Arjun Appadurai (1991), no se trata tanto de que historiadores y arqueólogos hablen los unos de los otros, sino los unos con los otros.

Sin poder negar que el interés de la arqueología por la historia es mayor que el de la historia por la arqueología (p. ej., ver Jack 1993), también en este caso el movimiento se tiene que demostrar andando. 
(....) We have all seen too many projects that are site specific, descriptive exercises; too many projects that end up as illustrations of history, despite our best intentions ${ }^{10}$ (Wesler 1996: 3).

Por ello, los arqueólogos y arqueólogas hemos de proporcionar resultados que contribuyan al conocimiento histórico, que no puedan ser ignorados por los colectivos que trabajan en problemáticas cercanas y que, si lo son, vaya en su detrimento. Lo cierto es que muchos investigadores se sienten a disgusto en relaciones profesionales asimétricas. De hecho, los proyectos más fructíferos suelen ser los que se elaboran desde la interdisciplinariedad y la transversalidad. Es precisamente a estos proyectos a los que Mayne -un historiador- se refiere al afirmar que no se puede seguir considerando a la arqueología as a field of inquiry that engages only with excavation data ${ }^{11}$ (Mayne 2008: 93-94). Trabajos como el que Kathleen Deagan (1983) lideró en San Agustin (Florida) han sido pioneros en este sentido (para ejemplos más recientes, ver Little 2007). En definitiva, se trata de plantear proyectos donde Historia y Arqueología sean interdependientes, sin estar la una al servicio de la otra.

\section{La Arqueología Histórica en España}

La pregunta con la que se titula este artículo tendría poco sentido en los países donde llevan años reflexionando sobre la génesis y el desarrollo de la arqueología histórica. Es el caso de los EE.UU. -pionero en el uso del término- o de Australia y de algunos de Latinoamérica, que adoptaron su empleo posteriormente. Por el contrario, y en términos generales, la arqueología histórica es todavía una gran desconocida en la academia española, a pesar de que la arqueología de gestión -pública, contractual, comercial, preventiva, etc.- sí viene desarrollando intervenciones en este ámbito desde hace tiempo, sobre todo en el marco de proyectos relacionados con las urgencias arqueológicas y/o con la gestión cultural de las ciudades, edificios y jardines históricos (González Marrero y Tejera 2011; Vela Cossío 2011).

En España, como en otros países europeos, el término resulta ciertamente extraño por los motivos que hemos expuesto antes. Nos atreveríamos a decir que la arqueología histórica se siente como algo foráneo, ajena al desarrollo de la Arqueología en nuestro país. Por asociación de ideas, hay quienes asumen que debe ser la arqueología referida a los períodos históricos -por oposición a los prehistóricos-, pero su uso es muy poco común. Tampoco es muy corriente en su acepción cronológica más restringida, con la salvedad del caso canario, donde sí parece haber un cierto consenso para referirse de este modo a las investigaciones en yacimientos con cronologías posteriores a la conquista española (ver, p. ej., Arnay de la Rosa 2009). No obstante, y aunque de modo todavía tímido, en los últimos años también empieza a arraigar en la Península el uso más acotado del término, sobre todo tras la paulatina incorporación de departamentos y centros de investigación a proyectos relacionados con la arqueología del colonialismo hispano-portugués y de la guerra civil, y la opción personal que han hecho sus investigadores e investigadoras. Por todo ello, resulta comprensible que no se haya desarrollado un debate en profundidad sobre el estatuto ontológico, epistemológico y metodológico de la arqueología histórica en nuestro país, aunque empiezan a publicarse trabajos al respecto (Azkárate y Escribano 2014). Es nuestra modesta intención en este artículo ofrecer un paso más en ese sentido.

Es verdad que ya existen publicaciones sobre la trayectoria de la arqueología histórica en España, pero sus objetivos son diferentes, pues principalmente se proponen ofrecer un catálogo de las intervenciones realizadas (Muñoz Villarreal 2006), aunque a veces se aluda también a temas de discusión teórico-metodológica interesantes (Vela Cossío 2011), algunos de los cuales retomaremos posteriormente. En consonancia con la tónica europea, también en España se prefieren las rúbricas cronológicas para hacer referencia a estos momentos. Rúbricas cronológicas que, por otra parte, y como nos comentaba uno de nuestros evaluadores, encajan mejor con nuestra realidad histórica e historiográfica que la de arqueología histórica. Entre ellas se encuentran la de "Arqueología Postmedieval" (p. ej. Amores 1997; Gutiérrez Lloret 1997; Padilla y Vila 1998 o Muñoz Villarreal 2006); la de "Arqueología Postclásica” (Quirós y Bengoetxea 2006); o las que mencionan la modernidad en diferentes combinaciones (p. ej. Bengoetxea 2004; Trujillo Yáñez 2004; Vela Cossío 2011). Para individualizar momentos más recientes, se utilizan las de "Arqueología Contemporánea" y "Arqueología Industrial", que tiene una fuerte carga conceptual (ver González Vergara 2014 para una síntesis reciente). Igualmente conceptuales son marcas del tipo "Arqueología del Contacto" (Tejera y Az- 
nar 1989; Hernández et al. 1996) o "Colonial" (Onrubia et al. 1998; Trujillo Yáñez 2004). Junto a la de arqueología histórica, son especialmente comunes en Canarias (González Marrero y Tejera 2011), y han nacido de la sensación de imprecisión que generaba reunir bajo la rúbrica de arqueología histórica "toda una serie de yacimientos que responden a realidades históricas diferentes" (Arnay de la Rosa 2009: 22). También retomaremos este punto más adelante.

Contrariamente a lo que podía haber ocurrido, esta profusión de denominaciones, como decíamos, no ha generado -con la excepción de la "Arqueología Industrial"- una reflexión en profundidad sobre el concepto de arqueología histórica. En algunos casos, incluso ha promovido cierta indiferencia, como la que se desprende al referirse a la arqueología de este periodo como "la arqueología histórica, postconquista, colonial $o$ como se la quiera llamar" (Arco et al. 1992: 38) [Las cursivas son nuestras].

\subsection{La arqueología histórica en la Academia española}

Aunque a primera vista pueda parecer contradictorio, se puede afirmar que, en España, la arqueología histórica "ha experimentado un desarrollo notabilísimo en los últimos treinta años" (Vela Cossío 2011: 75) y, a la vez, sostener que es una gran desconocida. Como ha ocurrido en todos los países donde la arqueología histórica se ha consolidado o está en proceso de hacerlo (Gilchrist 2005; Mayne 2008; Mehler 2012; Courtney 2013; Fournier y Velasquez 2014; Van Buren 2014), también en España empezó a generalizarse en el ámbito de la arqueología de gestión con el auge de los salvamentos arqueológicos a partir de los años 80. Sin embargo, como sucede también en la mayoría de los países europeos, todavía no ha desarrollado una infraestructura académica que le proporcione cobertura.

Este aún no-ser académico tiene unas repercusiones muy importantes. Recordemos que sólo la institucionalización de la arqueología histórica en EE.UU. supuso una reflexión profunda sobre su definición conceptual, su ámbito de aplicación, sus métodos de análisis, su lugar en el seno de la arqueología y sus relaciones con otras disciplinas, a la vez que permitió mejorar la formación de sus profesionales (Schuyler 2003). Precisamente, estos son los retos que tienen que encarar todavía la mayoría de países europeos (Mehler 2012, 2013), o mejor dicho, los inves- tigadores e investigadoras que empiezan a interesarse por ella. Al menos en España, no se trata de un desafío sencillo; ni siquiera existe un sentir general entre la comunidad arqueológica que lo plantee como una necesidad. Encontrar huecos (o introducir cambios) en los actuales programas docentes, obtener recursos para financiar proyectos de investigación, atraer a nuevos investigadores e investigadoras para garantizar el reemplazo generacional y, a la vez, fomentar la relación con los y las profesionales de la historia resulta complicado en un país donde la arqueología se vincula, principalmente, al estudio de la prehistoria, la protohistoria y las civilizaciones clásicas de la Antigüedad en el Mediterráneo y el Próximo Oriente (ver también González Marrero y Tejera 2011; Gutiérrez Lloret 2011; Olmo 2011-2012).

De momento, son escasas las universidades españolas que cuentan con programas docentes que incluyan asignaturas de arqueología histórica, por lo que es difícil suscitar interés entre el alumnado y abrir espacios de discusión teóricometodológica. Resolver este problema no resulta fácil. El estudio de la arqueología histórica necesitaría de una mayor integración universitaria (Courtney 2007; Mehler 2012) y de más transversalidad y movilidad curricular de la que es posible actualmente. Trabajar con las problemáticas históricas que le incumben requiere no solo un buen conocimiento de la cultura material y de sus posibilidades sino también de la aportación de otras fuentes de información (documentos históricos de diversa índole, historia oral, obras de literatura, filosofía, pensamiento científico, etc.). Sin duda, la tan glosada colaboración interdisciplinar, principalmente entre la historia y la arqueología, resultaría particularmente oportuna y mutuamente provechosa. Sin embargo, y hasta el momento, la arqueología histórica se encuentra en una especie de tierra de nadie. Aunque con excepciones cada vez más sobresalientes, desde la historia se siente la arqueología histórica como algo ajeno, y desde la prehistoria y la arqueología de la antigüedad, también. Sin duda, este sentir tiene importantes consecuencias a la hora de asignar recursos económicos a los proyectos y acciones de investigación, pues cuando se acostumbra a priorizar lo que se considera más próximo a lo propio, resulta desventajoso tener pocas y pocos investigadores interesados por la arqueología histórica en los paneles de toma de decisiones.

Tampoco nos cabe la menor duda que la arqueología histórica se vería beneficiada de existir 
una mayor convergencia de conocimiento entre la arqueología académica y la de gestión. De momento, la comunicación entre ambas sigue siendo insuficiente, al tener cada una sus propios canales de investigación y difusión, pese al afán de muchos y muchas por que sea de otro modo (Gutiérrez Lloret 2011; Olmo 2011-2012; Abejez 2012). Los proyectos de arqueología de gestión raramente se inician como proyectos de investigación, al estar motivados por la urgencia que plantea la necesidad del salvamento. Asimismo, los resultados de estas intervenciones se quedan en informes técnicos que aparecen de forma dispersa, fragmentada y, a menudo, tardía (ver sobre este aspecto, Salvatierra 1994; Criado 2002; Quirós 2005; Rodríguez Temiño 2006-2007), muy de acuerdo a cómo se han generado (honrosas excepciones incluyen, por ejemplo, los trabajos de AUDEMA -Auditores de Energía y Medio Ambiente S.A.- sobre Toledo (Carrobles y Morín 2014). Al responder a las necesidades de un mercado al que poco le interesa la investigación, normalmente no se publican, y mucho menos en las plataformas que se manejan desde la academia, lo cual no mejora precisamente su ya de por sí escuálido interés por el tema. En la escena más internacional ello equivale a su práctica invisibilización. Al apenas existir trabajos de síntesis ni "externalizarse" la información en revistas de ámbito internacional, muchos de los estados de la cuestión recientes desconocen (y por consiguiente no citan) lo que se lleva a cabo en España.

Sería terriblemente injusto, sin embargo, olvidar que la arqueología académica y la de gestión difieren en cuanto a sus tiempos y a las posibilidades que permiten a sus profesionales (ver González 2013). A pesar de que también en el mundo académico la investigación se vive cada vez más apresuradamente, siempre al servicio de unos curricula vitae crecientemente valorados al peso (lo que sin duda repercute en su calidad), la presión y los constreñimientos temporales siguen siendo todavía mayores en la arqueología de gestión. Solamente así se entiende mejor la escasa reflexión teórica que la caracteriza (ver Olmo 2011-2012); lo difícil que le resulta generar un conocimiento integral sobre el pasado, algo sobre lo que ya se reflexionó desde el principio de la moderna arqueología urbana (Heighway 1972; Biddle et al. 1973; VV.AA. 1982); y "la precaria situación de los estudios peninsulares que exceden el límite del medievo" (Barrachina y Escribano 2012: 219), precisamente por ser éste, fundamentalmente, el periodo sobre el que actúa.
Nos guste o no, los únicos proyectos de investigación financiados con viabilidad a largo plazo son los académicos, a pesar de que las intervenciones de la arqueología de gestión sean mayoritarias (González Marrero y Tejera 2011; González 2013). Por ello se ha afirmado que la colaboración entre ambos sectores pasa por incorporar la arqueología de gestión a los proyectos académicos (Gutiérrez Lloret 2011), aunque no esté claro el modo en que deba hacerse, pues la academia no siempre facilita la incorporación a sus proyectos a quienes no forman parte de ella.

Así pues, las incursiones de la academia española en la arqueología histórica son todavía bastante exiguas. En los últimos años, sin embargo, está creciendo el número de investigadores e investigadoras adscritos a diferentes universidades y centros de investigación interesados por sus problemáticas, especialmente por las relacionadas con los procesos del colonialismo hispano-portugués de época moderna y con la guerra civil española. Como apuntábamos anteriormente, algunos de estos investigadores, como en EEUU, proceden del campo de la prehistoria. La situación, por supuesto, no es del todo equiparable en España, donde el corte cronológico entre la historia y la prehistoria se sitúa mucho antes, y donde la arqueología histórica se nutre también de arqueólogos y arqueólogas de la antigüedad clásica y medievalistas, al igual que en otros países europeos (Courtney 2013). Aun así, igualmente estamos convencidos de que una comunicación fluida entre la arqueología histórica y la prehistórica no puede más que favorecer a ambas. Del mismo modo que es también de beneficio mutuo la relación entre los y las profesionales de la arqueología y de la historia (Jack 1993; Mayne 2008).

\subsection{La arqueología del colonialismo moderno}

En su artículo de 2011, Fernando Vela Cossío menciona, no sin un cierto grado de aflicción, el poco interés que la arqueología del colonialismo español ha suscitado en nuestro país. Si se tiene en cuenta que este asunto es uno de los más investigados en la arqueología histórica americana, ello podría resultar sorprendente. Sin embargo, si nos atenemos al desarrollo y peculiaridades de la arqueología peninsular, el asombro se desvanece rápidamente.

Una vez más, Canarias pone su particular nota de distinción, pues se lleva años trabajando sobre el tema (González Marrero y Tejera 2011) 
y es fácil entender por qué. Su propia trayectoria histórica la acerca a todos aquellos países de América, Asia, África y Oceanía que padecieron la conquista y colonialismo de la monarquía hispánica. Es por ello que, además de los proyectos asociados a la recuperación y puesta en valor del patrimonio arqueológico de la época que nos concierne, existen también otros trabajos que han estudiado la primera llegada de los peninsulares a la isla (Serra Ràfols 1960) y su relación con los habitantes nativos (Tejera 1992, 2004; Hernández et al. 1996; Borges y Borges 2000). De hecho, los historiadores enmarcan la ocupación de las Canarias dentro de la primera fase de la expansión de la monarquía hispánica hacia el Atlántico (Chaunu 1972; Martínez Shaw y Alfonso 1999) y consideran su conquista y colonización como una antesala de lo acaecido en América. Obviamente, comprender qué ocurrió en estas islas durante los siglos XIV y XV ayuda a entender mejor lo que aconteció posteriormente en el continente americano.

En contextos informales de discusión académica, muchas veces hemos debatido sobre el poco interés que la arqueología española ha mostrado por el estudio del colonialismo moderno. Ello contrasta con la gran tradición de estudios relativos al colonialismo de otras épocas, como el fenicio, griego o romano. A veces se apunta a un cierto complejo de culpabilidad ante el imperialismo español e incluso a traumas no superados (Crisis del 98 o la pérdida de las últimas colonias africanas de Guinea, en 1968, y el Sahara Español, en 1975). En esta misma línea, Paul Courtney, aunque refiriéndose al contexto más general de Europa, habla de collective amnesia and embarrassment about colonialism in Euro$p e^{12}$ (2009: 181). Personalmente, estas razones nos parecen poco convincentes. Dejarían en muy mal lugar a los arqueólogos que trabajan sobre este tema en Canarias y a un grupo muy nutrido de historiadores que se encuentran a la cabeza de la investigación sobre el colonialismo moderno tanto en España como en otros países europeos. Azkárate y Escribano aluden, en cambio, al contexto ideológico y político que caracteriza a la Europa de finales del s.XX y principios del XXI, pues

(....) interesa mucho más la construcción de la Europa altomedieval, germánica, carolingia, que el mea culpa por los excesos del colonialismo y el imperialismo (2014: 97).
Sin negar que esto esté sucediendo, continúa dejando sin explicar la gran pujanza que el tema ha tenido y tiene entre nuestros colegas historiadores. Nosotros más bien nos decantamos por unas razones más mundanas, restringidas al quehacer arqueológico y al desarrollo de nuestra disciplina en España. Así, al poco interés por las excavaciones fuera de casa se une el desarrollo mayoritario de la arqueología histórica en el campo de la arqueología de gestión, cuyos proyectos, por motivos obvios, se restringen al ámbito de nuestras fronteras. Por ello, es también en las Canarias donde se ha desarrollado principalmente el tema.

Recientemente, sin embargo, ambos hechos han empezado a cambiar, y han surgido nuevos proyectos de arqueología histórica interesados por el estudio del colonialismo hispano-portugués de época moderna. Los primeros proyectos y colaboraciones en el extranjero se iniciaron durante los años 90 del pasado siglo, en Canadá (Azkárate et al. 1992) y Perú (Vela Cossío 2009). Más recientemente se han añadido nuevos proyectos en Guinea Ecuatorial (González Ruibal et al. 2015), Etiopía (Fernández 2015), Taiwán (Cruz Berrocal 2015), Argentina (Azkárate et al. 2011; Azkárate y Escribano 2015), Canadá (Azkárate y Escribano 2015), Marruecos y Panamá, y se han comenzado también los trámites para iniciar otros en Guam (islas Marianas). Las sesiones organizadas por Javier Iñañez y André Teixeira en la 46 Conferencia Anual de la SHA en Leicester (Territory, settlement and material culture in the Iberian colonial empires (16-18th centuries), 2013); por María Cruz Berrocal y Sandra Montón Subías en la 78 Conferencia Anual de la SAA en Honolulu ("Entangling" Archaeology and History. Early Modern Colonialism in the Asia-Pacific Region, 2013); los seminarios de la Universidad Pompeu Fabra "Desencuentros culturales: una mirada desde la cultura material de las Américas" (Ruiz 2008) y "Archaeologies of Early Modern Spanish Colonialism" (MontónSubías et al. 2015); o la puesta en marcha de proyectos como "Tecnolonial" (Buxeda 2010), entre otros, son buena muestra de la efervescencia del tema en la academia española. Es interesante que los investigadores e investigadoras españolas estén cubriendo áreas -como las de Asía-Pacífico y África- que hasta la fecha han recibido poca atención.

Desafortunadamente, la mayoría de estos proyectos son todavía bastante desconocidos en el panorama internacional, donde normalmente no 
existe lo que no se publica en inglés. De hecho, las síntesis que se ofrecen sobre arqueología histórica en Europa desconocen algunos de los proyectos que, aunque en bajo número, llevan ya algunos años siendo dirigidos por arqueólogos y arqueólogas españolas.

\section{5. ¿Por qué una visión "restringida"?}

Afines a la corriente más extendida en el uso del término "arqueología histórica", para nosotros también tiene sentido entenderla como el estudio de los procesos que han configurado el mundo moderno y su evolución en el tiempo. De todos modos, aunque estamos de acuerdo con el contenido de la designación, la nomenclatura no nos acaba de convencer y somos conscientes de las suspicacias que levanta el término. Como señalaban también los evaluadores de este artículo, si la utilizamos es por comodidad y para hacernos entender, ya que en Europa, a diferencia de EEUU, modernidad e historia escrita no van de la mano.

Aunque las sociedades actuales son el producto de trayectorias históricas de muy larga duración -algunas de las cuales se originaron en nuestro pasado prehistórico más remoto- y a pesar de que esas trayectorias están plagadas de continuidades y permanencias, existen también acontecimientos históricos que han constituido verdaderos puntos de inflexión en el transcurso de la historia de la humanidad. En este sentido, la expansión de las monarquías ibéricas por el mundo -iniciada a finales de la Edad Media- originó cambios extremadamente significativos y de todo tipo: políticos, sociales, económicos y, sobre todo tras la primera circunnavegación del mundo en 1521, cognitivos. A partir de aquel momento, $\mathrm{y}$ aunque en un principio sólo afectase a sectores reducidos de la población mundial, se alteró sustancialmente la cosmovisión del ser humano, dando lugar a una nueva sensación de empoderamiento frente a la naturaleza. Todo ello marcó el inicio de lo que podríamos considerar como el primer orden verdaderamente mundial de la Historia. Creemos que la magnitud de los anteriores fenómenos les confiere una singularidad, por su carácter insólito, únicamente comparable -y sólo en sentido geográfico- a la primera expansión de los humanos por el planeta. Sin embargo, sólo ahora se toma conciencia de la globalidad y se multiplican las interacciones entre las diferentes poblaciones del mundo a un ritmo y escala (local, regional y, por primera vez, planetaria) nunca antes vividos (sobre el carácter único de este momento histórico ver, entre otros, Wallerstein 1974; Wolf 1982; Martínez Shaw y Alfonso 1999; Dussel 2000; Quijano 2000; Marks 2002; Gruzinski 2012).

La anterior visión de la arqueología histórica ha recibido críticas de diferente tipo. Se le ha achacado un talante eurocéntrico, y se la ha calificado de arbitraria y laxa. Por ejemplo, en España, principalmente desde Canarias, se ha incidido en el carácter distendido, impreciso, demasiado general y poco comprometido del término (Onrubia et al. 1998; Arnay de la Rosa 2009; González Marrero y Tejera 2011), pues supone un puro reflejo mimético y acrítico del vocabulario puramente neutral auspiciado por un cierto americanismo académico (Onrubia et al. 1998: 659). Por ello, lo hemos visto antes, se ha propuesto utilizar otros términos más acotados a las problemáticas tratadas, como el de arqueología colonial o el de arqueología del contacto.

Personalmente, sin embargo, pensamos que los anteriores calificativos resultan inmerecidos, e incluso nos atreveríamos a decir que son un síntoma de lo que los propios autores reconocen y denuncian: la ausencia de reflexión profunda sobre las implicaciones de la arqueología histórica (p. ej. González Marrero y Tejera 2011: 131). Ciertamente, da la sensación que muchas veces simplemente se ha producido una transposición cronológica del término, sin reparar demasiado en la argumentación conceptual que defiende esa temporalidad. En nuestra opinión, es perfectamente compatible conjugar el empleo de términos más circunscritos y el de uno más general e inclusivo, en tanto que aglutinante que los inserte dentro del marco teórico-epistemológico que defendemos. De hecho, esto es lo que ocurre en otras partes del mundo. El propio Orser (2012), tal vez el más acérrimo defensor de la acepción restringida de la arqueología histórica, la entiende como el estudio de los procesos de colonialismo global, racialización, capitalismo y eurocentrismo. Por lo tanto, la arqueología histórica casa perfectamente con la puesta en práctica de las arqueologías del colonialismo, del capitalismo, de la racialización e incluso del eurocentrismo. Por ello, tampoco creemos que se pueda afirmar que la arqueología histórica no está comprometida políticamente. Solamente si se la desvincula de su marco crítico original, sin atender a su genealogía, el término puede parecer aséptico.

Sin duda, la crítica más extendida -aunque a veces sea más acusación que crítica- se refiere a 
su supuesta condición eurocéntrica. Hay quienes estiman inaceptable (y políticamente incorrecto) situar a Europa en el centro de los desarrollos históricos y estudiar al resto del mundo sólo a partir de sus relaciones con ella (Little 1992, 2007; Pikirayi y Pwiti 1999; Reid y Lane 2004; Schmidt 2006; Mayne 2008). Por ello, se ha aludido a la necesidad de deslocalizar fuera de Europa el motor (o los motores) de la historia, algo que también se ha reclamado desde la antropología y la historia (Blaut 1993, 2000; Wong 1997; Frank 1998; Pomeranz 2000; Marks 2002; Beaujard 2005; Goody 2006; Hart 2008). Deseurocentrar la historia sin duda proporciona visiones diferentes y complementarias sobre la Historia del Mundo, pero no tiene porqué resultar incompatible con el reconocimiento de la singularidad del momento histórico al que nos referimos (en este sentido, por ejemplo, ver el capítulo 6 de Crossley 2008).

A la vez, se ha advertido sobre los "silencios" de investigación (Trouillot 1995), de diferente tipo, que crean las perspectivas eurocéntricas, como por ejemplo, desatender las respuestas locales que se produjeron ante la llegada del colonialismo europeo (Kinahan 2000). En sintonía con esta idea, algunos arqueólogos, que sobre todo trabajan en África, han expresado su preocupación por las consecuencias que puede tener el interés creciente de la arqueología histórica por estudiar los procesos coloniales en estos países (Schmidt y Walz 2007; Schmidt 2009). Así, por ejemplo, Peter R. Schmidt ha denunciado que sumerge

(...) African histories under a colonialcentric bias that reifies European agency rather that African agency ${ }^{13}$ (2009: 3).

Según estos autores, definir una África pre- y post- contacto europeo minimiza -o directamente ignora- las dinámicas internas, la diversidad cultural y el desarrollo histórico del continente, cuyos pueblos han interactuado no solo con los europeos sino con el resto del mundo desde antiguo (Robertshaw 2004; Mitchell 2005). Es muy curioso que esta última apreciación provenga de arqueólogos que trabajan en África. De confirmarse, significaría un comportamiento diferente con respecto a los otros continentes en el que sin duda convendría profundizar, dado que en el resto del mundo son precisamente estos momentos los que se hallan arqueológicamente infraestudiados en relación al registro pre-colonial.

Ante estas críticas, hay que admitir que es cierto que la historic sites archaeology fue, en sus ini- cios, un proyecto de fundación nacional destinado a enaltecer los vínculos entre EEUU y Europa. En 1955, por ejemplo, Jean Carl Harrington la relacionaba con los trabajos llevados a cabo en sites associated with the history of white men in North America $^{14}$ (1955: 1121) [el resaltado es nuestro]. Sin embargo, hace tiempo que la arqueología histórica ha dejado de ser eso (o sólo eso). Ya hemos visto que, con la generalización de este término durante los años 60 y 70 del pasado siglo, se incorporaron una serie de problemáticas que iban en un sentido muy diferente. De hecho, la mayoría de quienes defienden actualmente una visión cronológicamente restringida de la arqueología histórica afirman que uno de sus principales activos consiste en atender a la agencia no europea, que es precisamente la más infrarrepresentada en la documentación escrita.

Merece la pena repetir que, en nuestra opinión, la particularidad de la nueva etapa histórica que se abre con los procesos coloniales que se inician en el s.XV reside en su dimensión global. De hecho, entendemos su singularidad de manera similar a la de muchos estudios poscoloniales y decoloniales. Anibal Quijano (2000), por ejemplo, utiliza el término "colonialidad" para referirse al nuevo marco de relaciones internacionacionales -verdaderamente mundial- que se generó a partir de entonces, y sitúa los orígenes de la actual globalización en el nuevo patrón de poder mundial que empezó a gestarse. No podemos estar más de acuerdo con él que cuando afirma que "sea lo que sea lo que el término modernidad mienta, hoy involucra al conjunto de la población mundial y a toda su historia de los últimos 500 años, a todos los mundos o exmundos articulados en el patrón global de poder, a cada uno de sus segmentos diferenciados o diferenciables, pues se constituyó junto con, como parte de, la redefinición o reconstitución histórica de cada uno de ellos por su incorporación al nuevo y común patrón de orden mundial. Por lo tanto, también como articulación de muchas racionalidades" (Quijano 2000: 215) (ver también Dussel 2000). Este hecho es independiente de que se reconozca que, a partir de entonces, se genera un nuevo discurso de saber-poder -el eurocentrismoque naturaliza la nueva organización colonial del mundo y dispone

(....) la totalidad del espacio y del tiempo -todas las culturas, pueblos, y territorios del planeta, presentes y pasados- en una gran narrativa universal" en la que "Europa es -o ha sido siempre- simultáneamente el centro 
geográfico y la culminación del movimiento temporal (Lander 2000: 14).

Soslayar el estudio de este momento histórico y de los desarrollos que conlleva -por ejemplo, el eurocentrismo- puede tener consecuencias contrarias a las intenciones iniciales y originar nuevos silencios de investigación, como bien ha señalado Charles Orser (2012) en su reciente y contundente respuesta a muchas de las críticas vertidas desde la arqueología. Reconocer silencios en la investigación no puede conllevar la creación de otros nuevos. Asimismo, reconocer la singularidad a la que hacemos referencia y estudiar arqueológicamente los procesos que se desarrollan a partir de entonces no significa obviar otras singularidades históricas, ni ignorar que su genealogía puede encontrarse fuera de Europa (Frank 1998). Tampoco significa olvidar que, en otros momentos históricos, se produjeron desarrollos emparentados. Tal vez el ejemplo más claro sea, precisamente, el de los procesos coloniales e imperiales que, en diferentes lugares del mundo, sucedieron con anterioridad al s.XV. En ocasiones se ha afirmado que individualizar los iniciados en el s.XV impide una perspectiva comparada al fenómeno del colonialismo (Funari et al. 1999), aunque no se haya explicado por qué. Para nosotros, indagar en las peculiaridades del colonialismo moderno y profundizar en sus singularidades no equivale a convertirlo en incomparable, sino todo lo contrario: permite entender mejor lo que comparte (o no) con otros procesos coloniales y repercute en un mejor conocimiento del fenómeno colonial a lo largo de la historia.

Desde que Eric R. Wolf publicara su famoso libro Europe and the People Without History (1982), una de las consignas que más se ha repetido y repite en las publicaciones de arqueología histórica -precisamente desde la crítica al eurocentrismo- es la de la necesidad de "dar voz" a los otros, es decir, a quienes han sido tradicionalmente olvidados por la Historia tradicional. Independientemente de lo presuntuoso que personalmente nos parece auto-otorgarse la capacidad de hablar por boca de otros, nos resulta preocupante que desde esa voluntad se haya prestado escasa atención a los valores que han guiado la escritura de la historia y a la lógica con la que se escriben sus discursos (ver al respecto Montón-Subías 2010; Hernando 2012, 2015; Montón Subías y Lozano 2012). Por ello, independientemente de lo bienintencionada que pueda ser en origen, este deseo puede acabar participando de los mismos pecados que denuncia. Tenemos una anécdota que creemos que ilustra bien lo que estamos diciendo.

En una sesión celebrada en la reunión anual de la Asociación de Arqueólogos Europeos (EAA) en Helsinki (2012) sobre colonialismo, Richard Ciolek-Torello explicó cómo las estrategias subsistenciales de algunas poblaciones nativas americanas del Sur de California se habían visto profundamente alteradas tras la implantación de las misiones católicas en la zona. De este modo -comentaba- se truncaron unas dinámicas que se habían mantenido relativamente estables a lo largo de la historia de esas poblaciones. Pues bien, en la tanda de preguntas que se abrió posteriormente, una de las asistentes le tildó de eurocentrista por presentar una imagen inmovilista, según ella, de las poblaciones autóctonas y concebir que el cambio hubiera llegado únicamente con la presencia europea.

En nuestra opinión, este suceso constituye un ejemplo bastante claro de cómo funciona la lógica eurocéntrica más profunda, porque lo verdaderamente eurocéntrico, en nuestra opinión, radica en la necesidad de universalizar el cambio -un determinado tipo de dinámica histórica- a cualquier grupo humano. El cambio es, junto a la individualidad, el poder, la razón, el autocontrol, la violencia -en tanto que ejercicio para obtener, ejercer o recuperar el poder-, el crecimiento tecnológico o la competitividad, uno de los valores elogiados por el discurso dominante -eurocéntrico y androcéntrico- de la Historia y la Arqueología. Como hemos afirmado en otras ocasiones (Montón Subías y Lozano 2012), se trata de un discurso que únicamente enaltece valores, actitudes y capacidades asociadas a la llamada "masculinidad hegemónica" (Connell y Messerschmidt 2005) o a la "identidad individual" (Hernando 2012) propias de Occidente. La anécdota anterior resulta tanto más alarmante porque tras ella subyace la idea de que "asumir que otros seres humanos no tienen el mismo tipo de individualidad que nos caracteriza a nosotros supone desvalorizarles" (Hernando 2015: 21).

Hace ya tiempo que el feminismo ha denunciado que la lógica eurocéntrica -que también es patriarcal- se asienta sobre la ocultación y rechazo de los valores asociados a la relacionalidad, la interdependencia, la estabilidad, la perdurabilidad, la permanencia y la recurrencia en el transcurso de la historia. Por ello, la crítica al eurocentrismo debería necesariamente incluir una revisión en profundidad de todas estas otras dinámicas 
y valores. Si no, los sujetos subalternos que se quieren incorporar al discurso histórico seguirán hablando con una voz eurocéntrica. Precisamente, en uno de sus artículos, G. C. Spivak se preguntaba si ese sujeto subalterno podía hablar y, al hilo de lo que estamos comentando, afirmaba que "la teoría de los "efectos de sujeto/tema" pluralizados provoca la ilusión de socavar la soberanía del sujeto [occidental] mientras a menudo lo que hace es servir de cobertura para la supervivencia de ese mismo sujeto/tema de conocimiento" (1998: 1).

\section{Para seguir reflexionando}

En 1977, James Deetz finalizó In Small things forgotten animando a que, en vez de leer lo que se había escrito, observásemos lo que se había hecho: Don't read what we have written; look at what we have done ${ }^{15}$ (1977: 161). Entendemos que con ello se refería no sólo a la capacidad que el estudio de la cultura material tiene para acceder a un tipo de información que difícilmente nos pueden facilitar las fuentes escritas sino que incidía, además, en la particular aptitud de la arqueología para extraer, integrar e interpretar esa información.

Sin embargo, también expresaba la idea de que "sólo" la cultura material permitía un acercamiento real y objetivo al pasado y al conocimiento de la historia, algo en lo que han continuado y continúan insistiendo muchos arqueólogos y arqueólogas, para quienes la cultura material es mucho más representativa de la realidad que las fuentes escritas, al no estar sujeta -como ellas- a los intereses de quienes las escribieron o de quienes las encargaron, mostrando el mundo tal y como fue y no tal y como determinadas personas o grupos de poder quisieron describir.

En retrospectiva, hoy nos parece innecesario tener que priorizar entre la una o la otra. Cultura material y fuentes escritas no son excluyentes sino complementarias, por lo que defendemos un uso interdisciplinar de las mismas. Además, desde hace ya un tiempo, se ha ido incrementando la importancia y la presencia de la cultura material en los análisis e interpretaciones que otras disciplinas hacen del pasado. Es el caso de la propia historia (Carson 1978; Lubar y Kingery 1993; Hoskins 1998; Harvey 2009), que actualmente presta a la cultura material mucha mayor atención que en el pasado, sobre todo desde que ha comenzado a profundizar en aspectos como la vida cotidiana, el denominado mundo doméstico o el cimarronaje. No resulta extraño, por tanto, que cada vez más historiadores defiendan también un uso interdisciplinar de la información y la intensificación del diálogo con profesionales de diferentes ámbitos.

Por este motivo, estamos de acuerdo con Alan Mayne (2008) cuando advierte que no podemos instalarnos en la repetición de lemas que ya han sido claramente superados y que la historia también ha dado un giro hacia cuestiones que la arqueología lleva investigando desde hace tiempo. Por ello, afirmar que la historia no atiende al estudio de la cotidianidad y que solo se interesa por las grandes narrativas es, sencillamente, inexacto, como han demostrado con creces la Escuela francesa de los Anales, la microhistoria italiana o la Alltagsgeschichte alemana.

En este punto, es importante señalar que la arqueología histórica actúa a modo de crisol, donde diferentes evidencias -documentos escritos, cultura material, ilustraciones gráficas, tradición oral, etc.- pueden combinarse para complementar la comprensión de procesos que se han estudiado, tradicionalmente, únicamente desde la documentación escrita; o para tratar aquellos otros que han quedado escasamente registrados o que, simplemente, han sido ignorados por ella. A diferencia de Kit W. Wesler, quien se preguntaba what do we want to know that cannot be answered by historians? ${ }^{16}$ (1996: 2), no creemos que la arqueología histórica deba de centrarse únicamente en aquellas cuestiones para las que los historiadores no tengan respuesta, o restringirse a corroborar o refutar los textos o a "dar voz" a los excluidos de la historia oficial, como pretenciosamente nos atribuimos a veces. Más bien pensamos que se trata de construir una herramienta útil que habilite historias interdisciplinares que expliquen los procesos de formación del mundo moderno desde distintos espacios y realidades, unos procesos que forman parte de un desarrollo global que todavía sigue en marcha y necesita ser entendido.

La arqueología histórica, y en general toda la arqueología, presenta además ciertas características particulares que la hacen única frente a otras disciplinas que tratan con el pasado. Por un lado, destaca por su capacidad para proporcionar alternativas al positivismo de los datos escritos, no solamente describiendo lo que éstos no pudieron, supieron o quisieron recoger, sino yendo "más allá", en el sentido de investigar aquello que muchos historiadores -quizás excesivamente apegados a la literalidad del texto- ni se atrevie- 
ron a imaginar que pudo suceder. Es lo que se ha llegado a denominar como "arqueología negativa" (Fowles 2008; Vásquez 2012) que, a modo del psicoanálisis, se acerca a lo reprimido, a las ausencias, a lo que fue inapreciable en la época en que sucedió, explorando lo imperceptible para entender un pasado "subconsciente" que para muchos ni siquiera existió.

Por otro lado, permite establecer un vínculo emocional inmediato con la gente. Esta dimensión afectiva de los restos arqueológicos ya fue subrayada por Noël Hume al afirmar que

(....) the fruits of historic site archaeology can do much to make the work of historians more palatable to the public (...). The dedicated and painstaking work of the historian is hard to project in a visual form, in museum exhibits, slide-lectures, in movies or on televi$\operatorname{sion}^{17}$ (1964: 220).

Si algo debemos reconocerle a la arqueología es su virtud para "escenografíar" el pasado. La materialidad de los restos arqueológicos permite una visualización directa que ofrece una ventaja indudable tanto para transmitir el conocimiento histórico generado como para crear una vinculación afectiva con el pasado, imprescindible para el proceso de apropiación y valoración en el presente y para su propia preservación.

Asimismo, la arqueología histórica debe de insistir en su función social, un objetivo que se encuentra intrínsecamente ligado al desarrollo de la gestión del patrimonio cultural en estas últimas décadas, cuando ha entrado a formar parte fundamental de las estrategias de los Estados/Comunidades/Ayuntamientos en sus políticas educativas, culturales y, también, económicas. Potenciar los aspectos emocionales y prácticos de la arqueología, además de los puramente académicos, sobre todo en unos momentos en los que los estudios de Humanidades se encuentran seriamente cuestionados, tendría que formar parte consustancial del diseño de cualquier proyecto de investigación. Porque, no nos engañemos, si la arqueología no se hace visible o ignora su responsabilidad, función y beneficio social, se aleja de la sociedad a la que pretende y debe servir, provocando una indiferencia que puede ser la antesala de su desaparición.

\section{Agradecimientos}

No podemos finalizar la redacción de este artículo sin reconocer la ayuda prestada por muchos de nuestros colegas (procedentes de la prehistoria, la arqueología histórica y la historia). Manel Ollé, Alex Coello, Beatriz Marín Aguilera, Kay Tarble, Sergio Escribano, María Cruz Berrocal y María del Cristo González Marrero nos proporcionaron referencias bibliográficas y nos dejaron leer artículos suyos que todavía estaban en prensa. Almudena Hernando, Alfredo González-Ruibal y Apen Ruíz Martínez leyeron y comentaron el primer borrador de este texto, y nos proporcionaron sugerencias que han resultado fundamentales en su versión definitiva. Tampoco queremos dejar de mencionar el ingrato -aunque en este caso muy útil- trabajo de los evaluadores de Complutum. A todos y todas, nuestro más sincero agradecimiento.

Este artículo ha sido en parte posible gracias a la financiación recibida por el MINECO a través del Proyecto HAR2012-31927.

\section{Notas}

1. Pues este campo tuvo su principal desarrollo en los departamentos de antropología, donde la arqueología prehistórica tenía una larga tradición.

2. Significa cosas diferentes para gente diferente.

3. Estudia los restos culturales de las sociedades con escritura que fueron capaces de registrar su propia historia.

4. Es la arqueología de la expansión de las culturas europeas por el mundo a partir del siglo XV, y de su impacto e interacción con las culturas de los pueblos indígenas.

5. Llevar a cabo análisis comparativos de las transformaciones culturales que tuvieron lugar antes, durante y después del contacto con los europeos y el colonialismo.

6. La relación de la arqueología histórica con la prehistoria sigue siendo problemática (...), a veces se ofrece como campo de pruebas para el método y la teoría arqueológica, y a veces se esfuerza empecinadamente por definir una agenda independiente. 
7. Debería permitirnos decir sobre el pasado algo que no sería posible utilizando solamente un único tipo de evidencia. Este argumento resulta fundamental para rebatir la acusación de que la arqueología histórica es "una manera cara de aprender lo que ya sabemos".

8. "Criada de la historia".

9. Los historiadores que participan en proyectos arqueológicos como asesores a menudo sienten que sus directores desaprovechan, e incluso "castran" su trabajo.

10. Todos hemos visto demasiados proyectos centrados en un solo yacimiento que son solo descriptivos; demasiados proyectos que acaban únicamente ilustrando la historia, a pesar de contar con las mejores intenciones.

11. Como un campo de investigación que sólo utiliza los datos de la excavación.

12. Amnesia colectiva y bochorno ante el colonialismo europeo.

13. A las historias africanas bajo un sesgo colono-céntrico que materializa la agencia europea más que la africana.

14. Yacimientos asociados con la historia del "hombre blanco" en Norteamérica.

15. No leáis lo que hemos escrito; mirad lo que hemos hecho.

16. ¿Qué queremos conocer que no pueda ser contestado por los historiadores?

17. los frutos de la "arqueología de los yacimientos históricos" pueden contribuir en gran medida a hacer el trabajo de los historiadores más ameno para el público general (...) El arduo y meticuloso trabajo de los historiadores resulta difícil de proyectar de forma visual en exposiciones museísticas, en clases con diapositivas, en el cine o en la televisión.

\section{REFERENCIAS BIBLIOGRÁFICAS}

ABEJEz, L. J. (2011): Arqueología y política. La incorporación de los grupos indígenas al discurso del patrimonio. Sociedades Diversas, Sociedades en cambio. América Latina en perspectiva histórica (XII Encuentro-Debate, América Latina Ayer y hoy. Noviembre de 2009) (G. Dalla Corte; P. García; J. Laviña; N. Moragas; R. Piqueras; J. L. Ruiz-Peinado y M. Tous, coords.), Publicacions de la Universitat de Barcelona, Barcelona: 8-17.

Abejez, L. J. (2012): El Proyecto del Parque Ecoarqueológico de Xoclán, Mérida, Yucatán. Propuesta metodológica para la investigación arqueológica de un sitio maya en un contexto urbano. Tesis doctoral. Publicación digital de la Universitat de Barcelona, Barcelona. [URL: http://www.tdx.cat/handle/10803/80610] Acceso el 25/01/2014.

Amores, F. (1997): La Arqueología postmedieval en España. Panorama y perspectivas. Archeologia Posmedievale I, Firenze: 51-67.

Andrén, A. (1998): Between Artefacts and Texts: Historical Archaeology in Global Perspective. Plenum Press, New York.

Appadurai, A. (1991): Prefacio. La vida social de las cosas. Perspectiva cultural de las mercancias (A. Appadurai, ed.), CONACULTA/Ed. Grijalvo, México: 13-14.

Arco, M. C.; Jiménez, M. C.; Navarro, J. F. (1992): La arqueología en Canarias: del mito a la ciencia. Ediciones Canarias, Santa Cruz de Tenerife.

Arnay de la Rosa, M. (2009): La arqueología histórica en Canarias. El yacimiento sepulcral de la iglesia de Nuestra Señora de la Concepción de Santa Cruz de Tenerife. Arqueología Iberoamericana, 3: 21-36. [URL: http://www.laiesken.net/arqueologia/pdf/2009/AI0302.pdf] Acceso el 28/07/2014.

AzKarate, A.; Escribano, S. (2014): De la Arqueología Histórica a la Arqueología del Colonialismo. Una reflexión desde la experiencia europea. Arqueología de los primeros asentamientos urbanos españoles en la América Central y Meridional (F. Vela, ed.), Mairea Libros, Madrid: 85-107.

Azkarate, A.; Escribano, S. (e.p.): Thoughts on Early Spanish Colonialism through two American case studies: Basque Fisheries (Canada) and Sancti Spiritus Settlement (Argentina). Archaeologies of Early Modern Spanish Colonialism, Contributions to Global Historical Archaeology (S. Montón-Subías, M. Cruz Berrocal y A. Ruiz, eds.), Springer. 
Azkarate, A.; Hernández, J. A. y NúÑEz, J. (1992): Balleneros vascos del siglo XVI. Estudio arqueológico y contexto histórico (Chateau Bay, Labrador, Canadá). Gobierno Vasco, Vitoria-Gasteiz.

AzkÁRate, A.; Escribano, S.; SÁnchez, I.; Benedet, V. (2011): Recuperación y puesta en valor del Fuerte Sancti Spiritus, un asentamiento español en la Gran Cuenca del Río de la Plata (Puerto Gaboto, Santa Fe, Argentina). Informes y Trabajos 7, excavaciones en el exterior 2010. Ministerio de Educación, Cultura y Deporte, Madrid: 8-21.

BARRACHINA, C. P.; Escribano, S. (2012): Las producciones cerámicas vascas de época moderna: un caso práctico de arqueología histórica. Actas das IV Jornadas de Jovens em Investigação Arqueológica - JIA 2011, Vol. I (Faro, 11 a 14 de Maio de 2011) (J. Cascalheira y C. Gonçalves, eds.) Promontoria Monográfica, 16: 219-224.

Beaujard, P. (2005): The Indian Ocean in Eurasian and African World-Systems before the Sixteenth Century. Journal of World History, 16(4): 411-465.

BengoetXeA, B. (2004): Arqueología de la Edad Moderna: Valoración y reflexiones en torno a una disciplina en construcción: El ejemplo de la C.A.V.. KOBIE (Serie Anejos), 6(2): 667-682.

Biddle, M.; Hudson, D.; Heighway, C. (1973): The future of London Past. A survey of the archaeological implications of planning and development in the nation's capital. Rescue publication, $\mathrm{n}^{\circ} 4$, Worcester.

Blaut, J. M. (1993): The Colonizer's Model of the World: Geographical Diffusionism and Eurocentric History. Guilford, New York.

Blaut, J. M. (2000): Eight Eurocentric Historians. Guilford, New York.

Blouet, H. (2014): Caribbean Historical Archaeology. Encyclopedia of Global Archaeology (C. Smith, ed.), Springer, New York: 1156-1160.

Borges, E.; Borges, C. (2000): Las manifestaciones rupestres en el conjunto arqueológico de Achbinicó. XIII Coloquio de Historia Canario-Americana; VIII Congreso Internacional de Historia de America (AEA) (Las Palmas de Gran Canaria, 1998) (F. Morales Padrón, coord.) Cabildo de Gran Canaria, Las Palmas de Gran Canaria: 1824-1840.

BuxedA, J. (2010): Impacte tecnològic en el nou món colonial. Aculturació en arqueologia i arqueometria ceràmica (TECNOLONIAL). Resultados primera anualidad. QUARHIS, Ayuntamiento de Barcelona: Museu d'Història de la Ciutat, 6: 207-208.

CAldwell, J. R. (1959): The New American Archaeology: Its changing interests are bringing new kinds of understanding and a generalized view of its problems, Science, vol 129, $\mathrm{n}^{\circ} 3345$ : 303-307.

CAmpBell, M. (2002): History in Prehistory. The Oral Traditions of the Rarotongan Land Court Records. The Journal of Pacific History, 37(2): 221-238.

Campbell, M. (2008): The Historical Archaeology of New Zealand's Prehistory. Islands of Inquiry: Colonization, Seafaring and the Archaeology of Maritime Landscapes (G. Clark, F. Leach y S. O'Connor, eds.), Series Terra Australis 29: Papers in honour of Atholl Anderson. ANU E Press, Canberra: 339-350.

Carment, D. (1993): Archaeology and History in Central Australia. Australasian Historical Archaeology, 11: 139-141.

Carrobles, J.; Morín, J. (eds.) (2014): Los paisajes culturales de la ciudad de Toledo: Los cigarrales. Dehesas, espacios irrigados, torres, cigarrales y trincheras. British Archaeological Report International Series 2638, Archaeopress, Oxford.

Carson, C. (1978): Doing History with Material Culture. Material Culture and the Study of American Life (I. M. G. Quimby, ed.), Norton, New York: 41-64.

Charlton, T. H.; Fournier, P. (2008): Geographic overviews, the Americas (central): historical archaeology in Mexico. Encyclopedia of archaeology, Vol. 1 (D. Pearsall, ed.), Academic Press, New York: 182-192.

Chaunu, P. (1972): La expansión europea (siglos XIII al XV). Nueva Clío, Ed. Labor, Barcelona.

Cleland, Ch. E.; Fitting, J. E. (1968): The Crisis of Identity: Theory In Historic Sites Archaeology. The Conference on Historic Site Archaeology Papers 1967, 2(2): 124-138.

Connah, G. (1998): Pattern and purpose in historical archaeology. Australasian Historical Archaeology, 16: 3-7.

Connah, G. (2007): Historical archaeology in Africa: an appropriate concept?. African Archaeological Review, 24(1/2): 35-40. 
Connell, R. J.; Messerschmidt, J. W. (2005): Hegemonic masculinity: rethinking the concept. Gender \& Society, 19(6): 829-859.

CotTer, J. L. (1993): Historical Archaeology Before 1967. Historical Archaeology, 27(1): 4-9.

Courtney, P. (2007): Historians and Archaeologists: An English Perspective. Historical Archaeology, 41(2): 34-45.

Courtney, P. (2009): The Current State and Future Prospects of Theory in European Post-Medieval Archaeology. International Handbook of Historical Archaeology (T. Majewski y D. Gaimster, eds.), Springer, New York: 169-189.

Courtney, P. (2013): European Historical Archaeology. Transatlantic Perspectives. Historische Archäologie, Vol 2013, Issue 3, Kiel University: 1-5. [URL: http://www.histarch.uni-kiel.de/2013_Courtney_high. pdf] Acceso el 28/07/2014.

Criado, F. (2002): Apuntes sobre el Mercado y lo Público en Arqueología. Era-Arqueología, Edições Colibri, $n^{\circ}$ 4: $22-29$.

Crossley, P. K. (2008): What Is Global History? Polity Press, Cambridge.

Cruz Berrocal, M. (2015) (e.p.): Ilha Formosa, $17^{\text {th }}$ Century: Archaeology in Small Islands, History of Global Processes. Archaeologies of Early Modern Spanish Colonialism, Contributions to Global Historical Archaeology (S. Montón-Subías, M. Cruz Berrocal y A. Ruiz, eds.), Springer.

Dalglish, C. (ed.) (2013): Archaeology, the Public and the Recent Past. Society for Post Medieval Archaeology Monograph Series, vol 7. The Boydell Press, Woodbridge.

Deagan, K. (1983): Spanish St. Augustine: The Archaeology of a Colonial Creole Community. Academic Press, New York.

Deagan, K. (1996): Avenues of Inquiry in Historical Archaeology. Images of the Recent Past. Readings in Historical Archaeology (C. E. Orser, ed.), AltaMira Press, New York: 16-41.

Deagan, K.; Scardaville, M. (1985): Archaeology and History on Historic Hispanic Sites: Impediments and Solutions. Historical Archaeology, 19(1): 32-37.

DeEtz, J. (1977): In Small Things Forgotten: the archaeology of early American life. Garden City, Anchor Books, New York.

DeEtz, J. (1991): Archaeological Evidence of Sixteenth- and Seventeenth-Century Encounters. Historical Archaeology in Global Perspective (L. Falk, ed.), Smithsonian Institution Press, Washington D.C.: 1-10.

DeEtz, J. (1996): In Small Things Forgotten. An Archaeology of Early American Life. Expanded and revised version of 1989 edition, originally published in 1977. Anchor Books, Doubleday, New York.

Dussel, E. (2000): Europa, Modernidad y Eurocentrismo. La colonialidad del saber: eurocentrismo y ciencias sociales. Perspectivas lationoamericanas (E. Lander, ed.), CLASCO, Buenos Aires: 41-53.

Ferguson, L. (1980): Looking for the 'Afro' in Colono-Indian Pottery. Archaeological Perspectives on Ethnicity in America: Afro-American and Asian American Culture History (R. L. Schuyler, ed.), Baywood Publishing Company, Farmingdale, New York: 14-25.

FERnÁNDEZ, V. (e.p.): The Jesuit Mission to Ethiopia (1557-1632) and the origins of Gondarine architecture $\left(17^{\text {th }}-18^{\text {th }}\right.$ cent.). Archaeologies of Early Modern Spanish Colonialism. Contributions to Global Historical Archaeology (S. Montón-Subías, M. Cruz Berrocal y A. Ruiz, eds.), Springer.

Fontana, B. L. (1965): On the Meaning of Historic Sites Archaeology. American Antiquity, 31: 61-65.

Fournier, P.; Velasquez, V. (2014): Mexico: Historical Archaeology. Encyclopedia of Global Archaeology (C. Smith, ed.), Springer, New York: 4850-4863.

Fowles, S. M. (2008): Steps toward an archaeology of taboo. Religion, Archaeology, and the Material World, (L. Fogelin, ed.), Center for Archaeological Investigations, Occasional Paper No. 36, Southern Illinois University Press, Carbondale: 15-37.

Frank, G. A. (1998): ReOrient: Global Economy in the Asian Age. University of California Press, Berkeley.

FREDERICKSEN, C. F. K. (2000): History and prehistory: Essential dichotomy or arbitrary separation? Australian Archaeology, 50: 94-97.

FunARI, P. P. A. (1999): Historical archaeology from a world perspective. Historical Archaeology: Back from the Edge (P. P. A. Funari, M. Hall y S. Jones, eds.), Routledge, London: 37-66. 
FunARI, P. P. A. (2008): La Arqueología Histórica mundial y latinoamericana en las últimas dos décadas. Revista de Arqueología Histórica Argentina y Latinoamericana, 2: 11-15.

Funari, P. P. A.; Hall, M.; Jones, S. (eds.) (1999): Historical Archaeology: Back from the Edge. Routledge, London.

Gilchrist, R. (2005): Introduction: scales and voices in world historical archaeology. World Archaeology, 37(3): 329-336.

GonZÁLEZ, D. (2013): Del precariado a la nada. La situación laboral de la Arqueología Comercial en el Estado Español a principios del s. XXI. Arqueología Pública en España. (J. Almansa, ed.), JAS Arqueología, Madrid: $151-168$.

GonzÁlez Vergara, O. (2014): El arqueólogo industrial del s.XXI. Retos y paradigmas de una disciplina arqueológica para el mundo contemporáneo. Arqueoweb, 15: 68-80.

GonzÁlez Marrero, M. Del C.; Tejera, A. (2011): La arqueología medieval en las Canarias: una asignatura pendiente. Boletín de Arqueología Medieval, 15: 127-164.

GonzÁlez-Ruibal, A.; Picornell, Ll.; SÁnchez-Elipe, M. (e.p.): Colonial encounters in Spanish Equatorial Africa $\left(18^{\text {th }}-20^{\text {th }}\right.$ centuries). Archaeologies of Early Modern Spanish Colonialism. Contributions to Global Historical Archaeology (S. Montón-Subías, M. Cruz Berrocal y A. Ruiz, eds.), Springer.

Goody, J. (2006): The Theft of History. Cambridge University Press, Cambridge.

GruZINSKI, S. (2012): L'aigle et le dragon. Démesure européenne et mondialisation au XVIe siècle. Paris, Fayard.

GutiérRez Lloret, S. (1997): Arqueología. Introducción a la historia material de las sociedades del pasado. Universidad de Alicante, Valencia

GutiérRez Lloret, S. (2011): La arqueología ensimismada. El futuro de la arqueología en España. (J. Almansa, ed.), JAS Arqueología, Madrid: 111-117.

HaLl, M. (2000): Archaeology and the Modern World: colonial transcripts in south Africa and the Chesapeake. Routledge, London.

Hall, M.; Silliman, S.W. (2006): Introduction: Archaeology of the Modern World. Historical Archaeology (M. Hall y S.W. Silliman eds.), Blackwell, Malden, Oxford y Victoria: 1-19.

Harrington, J. C. (1955): Archaeology as an Auxiliary Science to American History. American Anthropologist, 57(6): 1121-1130.

Hart, J. (2008): Empires and Colonies. Polity Press, Cambridge.

Harvey, K. (2009): History and Material Culture: A Student's Guide to Approaching Alternative Sources. Routledge, Oxon y Nueva York.

Heighway, C. M. (1972): The erosion of history: Archaeology and Planning in Towns: a study of history towns affected by modern development in England, Wales and Scotland. Council for British Archaeology, London.

Hernández, C. M.; Alberto, V.; Barro, A.; Borges, E.; Eugenio, C. Ma; Velasco, J.; Rivero, Ma D.; Matos, L.; Febles, J. V.; Larraz, A.; GonzÁlez, Ma C. (1996): Las Cuevas de Achbinicó (Candelaria, Tenerife): un Proyecto de Arqueología Prehistórica e Histórica. El Museo Canario no LI. Las Palmas de Gran Canaria: 29-58.

Hernando, A. (2012): La fantasía de la individualidad. Katz, Buenos Aires.

Hernando, A. (2015) (e.p.): ¿Por qué la arqueología oculta la importancia de la comunidad? Trabajos de Prehistoria, 72.

Hicks, D.; Beaudry, M. C. (2006): Introduction: the place of historical archaeology. The Cambridge Companion to Historical Archaeology. (D. Hicks y M. C. Beaudry, eds), Cambridge University Press, Cambridge: $1-9$.

Hoskins, J. (1998): Biographical Objects: How things tell the stories of people's lives. Routledge, London.

Jack, I. (1993): Historical Archaeology and the Historian. Australasian Historical Archaeology, 11: 130138.

Jamieson, R. W. (2004): Bolts of Cloth and Sherds of Pottery: Impressions of Caste in the Material Culture of the Seventeenth Century Audiencia of Quito. The Americas, 60(3): 431-446. 
Johnson, M. (1996): An Archaeology of Capitalism. Wiley-Blackwell, Oxford.

KinAHAn, J. (2000): Cattle for beads: the archaeological of historical contacts and trade on the Namib coast. Studies in African Archaeology 17. Department of Archaeology and Ancient History, University of Uppsala, and Namibia Archaeological Trust, Windhoek.

LANDER, E. (2000): Ciencias sociales: saberes coloniales y eurocéntricos. La colonialidad del saber: eurocentrismo y ciencias sociales. Perspectivas lationoamericanas. (E. Lander, ed.), CLASCO, Buenos Aires: $11-40$.

Leone, M. P.; РотteR, P. B. (1988): Introduction: issues in historical archaeology. The Recovery of Meaning. (M. P. Leone y P. B. Potter, eds.), Smithsonian Institution Press, Washington D.C.: 1-22.

Leone, M. P.; Potter, P. B. (1999): Historical Archaeologies of Capitalism. Kluwer Academic/Plenum Publishers, New York.

Lightfoot, K. G. (1995): Culture Contact Studies: Redefining the Relationship between Prehistoric and Historical Archaeology. American Antiquity, 60(2): 199-217.

LitTLE, B. (1992): Text-aided archaeology. Text-aided archaeology. (B. Little, ed.), CRC Press, Boca Raton, Fla: $1-6$.

LittLe, B. (1994): People with History: An Update on Historical Archaeology in United States. Journal of Archaeological Method and Theory, 1(1): 5-40.

Little, B. (2007): Topical Convergence: Historical Archaeologists and Historians on Common Ground. Historical Archaeology, 41(2): 10-20.

Lowenthal, D. (1985): The past is a foreign country. Cambridge University Press, Cambridge.

Lubar, S.; Kingery, D. (eds.) (1993): History from Things: Essays on Material Culture. Smithsonian Institution Press, Washington.

Marks, R. B. (2002): The Origins of the Modern World: A Global and Ecological Narrative from the Fifteenth to the Twenty-first Century. Rowman and Littlefield, Lanham, Maryland.

Martínez Shaw, C.; Alfonso, M. (1999): Europa y Los Nuevos Mundos: Siglos XV-XVIII. Ed. Síntesis, Madrid.

Mayne, A. (2008): On the Edges of History: Reflections on Historical Archaeology. The American Historical Review, 113(1): 93-118.

MehLER, N. (2012): Written sources in post-medieval archaeology and the art of asking the right questions. Studies in Post-Medieval 4: Written and iconographic sources in post-medieval archaeology. (J. Žegklitz, ed.), Archaia, Prague: 11-24.

MehleR, N. (2013): Globalization, Immigration, and Transformation: Thoughts from a European Perspective. Historical Archaeology, 47(1): 38-49.

Mitchell, P. J. (2005): African Connections: Archaeological Perspectives on Africa and the Wider World. AltaMira Press, Walnut Creek.

Montón-SubíAs, S. (2010): Maintenance Activities and the Ethics of Care. Situating Gender in European Archaeologies. (L. H. Dommasnes, T. Hjørungdal, S. Montón-Subías, M. Sánchez Romero y N. Wicker, eds.), Archaeolingua, Budapest: 23-33.

Montón Subías, S.; Lozano, S. (2012): La Arqueología Feminista en la Normatividad Académica, Complutum, 23(2): 163-176.

Montón-Subías, S., Cruz Berrocal, M.; Ruiz, A. (e.p.): Archaeologies of Early Modern Spanish Colonialism. Springer.

Moreland, J. (2001): Archaeology and Text. Duckworth, London.

Moreland, J. (2006): Archaeology and Texts: Subservience or Enlightenment. Annual Review of Anthropo$\log$, , 35: 135-151.

Muñoz Villarreal, A. (2006): Desarrollo de la Arqueología Histórica en España. Gabinete de Arqueología, $n^{0}$ 5: 137-145.

NoËL Hume, I. (1964): Archaeology: Handmaiden to History. The North Carolina Historical Review. 41(2) (April): 214-225.

OLmo, L. (2011-2012): Un arqueólogo en la ciudad: en los inicios de un ensayo. CuPAUAM, № 37-38: 39-52. 
Onrubia, J.; Rodríguez, C. G.; SÁenz, J. I.; GonzÁlez, M. C.; Olmo, S. (1998): Los materiales 'históricos' de la Cueva Pintada de Gáldar (Gran Canaria). Una primera aproximación al contexto de las series coloniales bajomedievales y modernas (S. XV-XVI). XII Coloquio de Historia Canario-Americana (1996), vol. I (F. Morales Padrón, coord.), Ediciones del Cabildo Insular de Gran Canaria, Las Palmas de Gran Canaria: 643-674.

Orser, C. E. (1996): A Historical Archaeology of the Modern World. Plenum Press, New York.

Orser, C. E. (2000): Introducción a la Arqueología Histórica. Tridente, Buenos Aires.

Orser, C. E. (2012): An archaeology of eurocentrism. American Anthropologist, 77(4): 737-755.

Orser, C. E.; Fagan, B. M. (1995): Historical Archaeology. Harper Collins College Publishers, New York.

Padilla, J. I.; Vila, J. Ma (coord.) (1998): Cerámica medieval i postmedieval. Circuits productius $i$ seqüències culturals. Monografies d'arqueologia medieval i postmedieval GRAMP.-UB. Publicacions Universitat de Barcelona, Barcelona.

Pikirayi, I.; Pwiti, G. (1999): States, traders and colonists: Historical archaeology in Zimbabwe. Historical Archaeology, 33(2): 73-89.

Politis, G. C. (2002): Acerca de la Etnoarqueología en la América del Sur. Horizontes Antropológicos, año 8, no 18: 61-91.

Pomeranz, K. (2000): The Great Divergence: China, Europe, and the Making of the Modern World Economy. Princeton University Press, Princeton.

Posnasky, M.; DeCorse, C. R. (1986): Historical Archaeology in Sub-Saharan Africa-A Review. Historical Archaeology, 20(1): 1-14.

PykLes, B. (2008): The Recent Past: A Brief History of Historical Archaeology in the United States. The SAA Archaeological Record (May), 8(3): 32-34.

PykLes, B. (2010): Excavating Nauvoo. The Mormons and the Rise of Historical Archaeology in America. University of Nebraska Press, Lincoln, NE.

Quijano, A. (2000): Colonialidad del Poder, Eurocentrismo y América Latina. Colonialidad del Saber, Eurocentrismo y Ciencias Sociales. (E. Lander, ed.), CLACSO, Buenos Aires: 201-246.

Quirós, J. A. (2005): ¿Excavar en las ciudades o historiar las ciudades? El debate sobre la Arqueología Urbana a la luz de algunas experiencias europeas. Arqueología y territorio medieval, 12(1): 107-132.

Quirós, J. A.; Bengoetxea, B. (2006): Arqueología III. Arqueología postclásica. UNED, Madrid.

ReID, A.; LANE, P. (2004): An introductory consideration of scope and potential. African Historical Archaeologies. (A. Reid y P. Lane, eds.), Kluwer Academic/Plenum Publishers, New York: 1-32.

Robertshaw, P. (2004): African Historical Archaeology(ies): Past, Present and a Possible Future. African Historical Archaeologies. (A. Reid y P. Lane, eds.), Kluwer Academic/Plenum Publishers, New York: 375-391.

Rodríguez-Alegría, E. (2005): Eating Like an Indian: Negotiating Social Relations in the Spanish Colonies. Current Anthropology, 46(4): 551-573.

Rodríguez Temiño, I. (2006-2007): Pisar la historia. Revista d'Arqueologia de Ponent, nº 16-17: 239-256.

Ruiz, A. (2008): Desencuentros Culturales: Una Mirada desde la Cultura Material de las Américas. Cuadernos de Arqueología Mediterránea 17. Ediciones Bellaterra, Bellaterra.

Salvatierra, V. (1994): Historia y desarrollo del modelo andaluz de Arqueología. Trabajos de Prehistoria, 51(1): 1-13.

Schmidt, P. R. (2006): Historical archaeology in Africa: Representation, social memory, and oral traditions. Rowman AltaMira, Oxford.

Schmidt, P. R. (2009): What is Postcolonial about Archaeologies in Africa. Postcolonial Archaeologies in Africa. (P. R. Schmidt, ed), SAR Press, Santa Fe: 1-20.

Schmidt, P. R.; Walz, J. R. (2007): Re-Presenting African Pasts through Historical Archaeology. American Antiquity, 72(1): 53-70.

SchuYler, R. L. (1970): Historical and Historic Sites Archaeology as Anthropology: Basic Definitions and Relationships. Historical Archaeology 4: 83-89. 
SCHUYLER, R. L. (1976): Images of America: the contribution of historical archaeology to national identity. Southwestern Lore, Journal of the Colorado Archaeological Society 42 (4): 27-39.

SchuYler, R. L. (2003): The second Largest City in The English-Speaking World. John L. Cotter and The Historical Archaeology of Philadelphia, 1960-1999. Philadelphia and the Development of Americanist Archaeology (D. D. Fowler y D. R. Wilcox, eds.), The University of Alabama Press, Tuscaloosa: 156-164.

SchuYler, R. L. (2010): Foreword. Excavating Nauvoo. The Mormons and the Rise of Historical Archaeology in America. (B. Pykles), University of Nebraska Press, Lincoln, NE: ix-xiii.

Senatore, M. X. (2007): Arqueología e historia en la colonia española de Floridablanca (Patagonia, siglo XVIII). Editorial Teseo, Buenos Aires.

Serra Ráfols, J. De C. (1960): Memoria de la excavación del Castillo de Rubicón (abril de 1960). Revista de Historia canaria, Tomo 26. Año 33. No 131-132: 357-370.

Sheppard, P.; Walter, R.; Aswani, S. (2004): Oral tradition and the creation of Late Prehistory in Roviana Lagoon, Solomon Islands. A Pacific Odyssey: Archaeology and Anthropology in the Western Pacific. Papers in Honour of Jim Specht (V. Attenbrow y R. Fullagar, eds.). Records of the Australian Museum, Supplement 29. Australian Museum. Sydney: 123-132.

Sмiтн, I. (2014): Oceania: Historical Archaeology. Encyclopedia of Global Archaeology. (C. Smith, ed.), Springer, New York: 5549-5559.

South, S. (ed.) (1994): Pioneers in Historical Archaeology: Breaking New Ground. Plenum Press, New York.

SpivaK, G. C. (1998): ¿Puede hablar el sujeto subalterno? [Trad. de José Amícola del original de 1994: Can the Subaltern Speak? Colonial Discourse and Post-Colonial Theory: A Reader. (P. Williams y L. Chrisman, eds.), Columbia University Press, New York: 66-111]. Orbis Tertius, III(6): 1-44.

Tarble, K. (2015) (e.p.): Historical Archaeology and the Politics of Empowerment in Venezuela. Archaeologies of Early Modern Spanish Colonialism. Contributions to Global Historical Archaeology (S. Montón-Subías, M. Cruz Berrocal y A. Ruiz, eds.), Springer.

TAYLOR, T. (2008): Prehistory vs. archaeology: Terms of engagement. Journal of World Prehistory, 21(1): $1-18$.

Tejera, A. (1992): Majos y europeos. El contacto de culturas en Lanzarote en los siglos XIV y XV. Un precedente americano. Serie Informes $\mathrm{n}^{\mathrm{o}}$ 33, Secretariado de Publicaciones de la Universidad de La Laguna, La Laguna de Tenerife.

Tejera, A. (2004): Canarios, taínos y europeos de los siglos XIV y XV (Un modelo de contacto interétnico). Anuario de estudios atlánticos, 50(2): 809-836.

Tejera, A.; Aznar, E. (1989): El asentamiento franconormando de "San Marcial del Rubicón" (Yaiza, Lanzarote). Un modelo de Arqueología de contacto. Ayuntamiento de Yaiza, Santa Cruz de Tenerife.

Therrien, M. (2002): Estilos de vida en la Nueva Granada. Teoría y Práctica en la arqueología histórica en Colombia. Arqueología de Panamá La Vieja. Avances de investigación. (B. Rovira y G. Martin, eds.), Patronato de Panamá La Vieja, Panamá: 19-38.

Tostevin, G. B. (2007): Social Intimacy, Artefact Visibility, and Acculturation Models of Neanderthal-Modern Human Interaction. Rethinking the Human Revolution: New Behavioral and Biological Perspectives on the Origins and Dispersal of Modern Humans. (P. A. Mellars, K. V. Boyle, O. Bar-Yosef y C. B. Stringer, ed.), McDonald Institute for Archaeological Research Monographs. Oxbow Books, Cambridge: 341-357.

Treganza, A. E. (1954): Fort Ross: A Study in Historical Archaeology. Reports of the University of California Archaeological Survey no 23, Berkeley.

Trouillot, M. R. (1995): Silencing the Past: Power and the Production of History. Beacon Press, Boston.

Trujillo Yañez, G. A. (2004): Nuevos Datos para la Historia de la Arqueología «histórica» en Canarias. Faykag Revista Canaria de Arqueología 1. [URL: http://www.personales.ulpgc.es/emartin.dch/faykag/ faykag1_gustavo.pdf] Acceso el 28/02/2014.

VAn Buren, M. (2014): Hispanic South America: Historical Archaeology. Encyclopedia of Global Archaeo$\log y$ (C. Smith, ed.), Springer, New York: 3375-3382. 
VÁsqueZ, D. (2012): La dignidad del pasado: sobre la construcción de las realidades a través de la arqueología. La arqueología social latinoamericana: de la teoría a la praxis ( $\mathrm{H}$. Tantaleán y M. Aguilar, comps.), Universidad de los Andes, Bogotá: 141-164.

Veit, R. (2007): A Brief History of the Society for Historical Archaeology. Society for Historical Archaeology. [URL: http://www.sha.org/documents/HistoryoftheSHA.pdf] Acceso el 25/01/2015.

Vela Cossío, F. (2009): San Miguel de Piura, Primera Fundación Española en el Perú. Informe de Bases y Avance del Plan Director del Sitio Arqueológico de Piura la Vieja, La Matanza (Piura, Perú). Mairea Libros, Madrid.

Vela Cossío, F. (2011): El desarrollo de la arqueología histórica en España. Algunas experiencias recientes en la ciudad de Madrid. Canto Rodado: Revista especializada en patrimonio 6: 75-115.

Voss, B. L. (2012): Status and Ceramics in Spanish Colonial Archaeology. Historical Archaeology 46 (2): 39-54.

VV.AA. (1982): Archéologie urbaine. Actes du colloque international (Tours, 17-20 novembre 1980). Conseil Supérieur de la Recherche Archéologique, Sous-direction de l'archéologie, AFAN (Association pour les fouilles archéologiques nationales), Imprimerie nationale, Paris.

Walker, I. C. (1967): Historic Archaeology. Methods and Principles. Historical Archaeology, 1: 23-34.

Wallerstein, I. (1974): The Modern World System: Capitalist Agriculture and the Origins of the European World Economy in the Sixteenth Century. Academic Press, San Diego.

WesLer, K. W. (1996): The Archaeology of History. Ohio Valley Historical Archaeology 11: 1-5.

WiLEy, C. J. (2008): Collective Memory of the Prehistoric Past and the Archaeological Landscape. Nebraska Anthropologist, 23: 80-93.

WILKIE, L. A. (2005): Inessential archaeologies: problems of exclusion in Americanist archaeological thought. World Archaeology 37 (3): 337-351.

Wolf, E. R. (1982): Europe and the People Without History. University of California Press, Berkeley.

Wong, R. B. (1997): China Transformed: Historical Change and the Limits of European Experience. Cornell University Press, Ithaca. 